\title{
Molecular Perspective Review of Biochemical Role of Nucleobases Modified by Oxidative Stress
}

\author{
Piotr Cysewski ${ }^{1,2}$ \\ ${ }^{1}$ Department of Physical Chemistry, Collegium Medicum in Bydgoszcz, Nicolaus Copernicus University in Toruń, \\ ul. Kurpińskiego 5, 85-950 Bydgoszcz, Poland \\ ${ }^{2}$ Department of General Chemistry, University of Technology and Life Sciences in Bydgoszcz, \\ ul. Seminaryjna 3, 85-326 Bydgoszcz, Poland \\ e-mail: piotr.cysewski@cm.umk.pl
}

(Received: 2 December 2009; revised: 24 February 2010; accepted 10 March 2010; published online: 20 April 2010)

\begin{abstract}
Numerous damages to cellular DNA are imposed by oxidative stress. Formation of stable products resulting from oxidation of nucleobases is one of many observed consequences. The oxidized species constitute a class of heterocyclic compounds with great diversities of physicochemical properties. Modified nucleosides significantly differ from their canonical protoplasts by tautomeric equilibriums, protolytic properties in the gas phase and water solution, they have altered oxidative susceptibility and $\mathrm{N}$-glycosidic bond stabilities. However, what is most important, they have overwhelmingly altered pairing properties, which are directly responsible for observed cytotoxic properties of these lesions. Besides, since many analogues are structurally different with respect to canonical bases their presence in DNA must impose many energetic, structural and dynamic modifications. These aspect are reviewed as fruits of project no 39 supported by computational grant in Poznań Supercomputing and Networking Center (PSNC, Poland).
\end{abstract}

Keywords: oxidative DNA damage, reactive oxygen species, hydroxyl radical modified nucleobases, tautomerism, protolytic properties, $\mathrm{N}$-glycosidic bond, miscoding, aromaticity, oxidative susceptibility

\section{INTRODUCTION}

During normal metabolism of aerobic organisms [1-3] reactive oxygen species (ROS) are natural by products of non-pathological cell activities. They are formed as necessary intermediates in a variety of normal biochemical reactions. The intrinsic source of non-pathological amount of radical species comes from respiration in mitochondria and reduction of oxygen along the electron transport chain. Also a variety of enzymes are considered as endogenous source of ROS as, for example, used in host defense against invading pathogens [4]. Intercellular signaling also involve an elevated level of oxygen radicals [5]. On the other hand, apart form endogenous origin, there are diverse exogenous sources of oxygen species [1]. Although life evolved in aerobic conditions along with precise mechanisms protecting from the cytotoxic nature of ROS, the exposure to environmental stress such as UV, ionizing radiation, cytokines, chemotherapeutic drugs, chemical carcinogens, environmental toxic agents of pollution or just heat (hyperthermia) can result in significant damage to cell structure and its components [1-3]. Because ROS have important physiological functions the antioxidant defense systems cannot provide complete protection from harmful effects of ROS. Superoxide radical $\left(\mathrm{O}_{2}{ }^{-}\right)$, hydrogen peroxide $\left(\mathrm{H}_{2} \mathrm{O}_{2}\right)$ and hydroxyl radical ( $\mathrm{OH})$ along with other non-oxygen radicals $[1,2]$ impose a significant challenge to cellular integrity for potential damages to DNA, lipids, proteins and other macromolecules [1-3]. The reactivity of hydroxyl radical toward all nucleobases gives rise to an extensive range of products leading to nucleobases modifications, single- and double-strand breaks, cross-linking and formation of apurinic/apyrimidinic lesions [6,7]. It has been demonstrated [8-10] that many of these DNA modifications are toxic and/or mutagenic [1-3]. Modern instrumental development in chemical analysis enables measurement of $p p b$ (part per billion) concentrations. This is very important since yields of oxygen-derived radicals and their nonradical precursors are very low in vivo. Formation of a large number of free radical-induced derivatives of DNA bases was demonstrated in many irradiation and chemical experiments both in vivo and in vitro conditions of DNA and DNA-protein complexes (chromatin) [1-3, 8-10]. The use of gas chromatography-mass spectrometry with se- 
lected-ion-monitoring technique (GCMS/SIM) proved steady state levels of such derivatives as 2-hydroxyadenosine (AA), 8-oxoadenosine (AB), fapy adenosine (AC), 8-oxoguanosine (GA), xanthosine (GB), fapy guanosine (GC), 5-hydroxycytidine (CA), cytidine glycol (CB), 5,6-dihydroxycytidine (CC), 6-hydroxy-5,6-dihydrocytidine (CD), 5-hydroxy-5,6-dihydrocytidine (CE), 5-hydroxy-methyluridine (TA), thymidine glycol (TB), 5-hydroxy-5,6-dihydrothymidine (TC), 5,6-dihydrothymidine (TD), 6-hydroxy5,6-dihydrothymidine (TE), formyluridine (TF), isodialuric acid (UA), 5,6-dihydroxyuridine (UB), 5-hydroxyuridine (UC), 5-hydroxy-5,6-dihydrouridine (UD) and uridine glycol (UE). Although the formation of oxidative DNA lesions such as, for example, 8-oxogunine does not always involve oxygen-derived free-radical species [11], the accumulated evidences suggest strong correlation between the level of nucleobases derivatives and disease states [12-15] as it was demonstrated by some examples collected in Table 1. Nowadays, oxidative damage to DNA building blocks are used as marker for prediction of cancer develop- ments $[10,16]$. This has a formal consequence in establishing The European Standards Committee on Oxidative DNA Damage (ESCODD) for controlling and standardize measurements of background levels of oxidative damage to DNA in human cells [16].

The biochemical consequences of oxidative damage to nucleobases can be related to structural and dynamic changes of polynucleotide chain after modification. In normal conditions the level of oxidation is $1-200$ per $10^{5}$ intact nucleosides. Even such small concentration are noxious since they can accumulate with age or diseases progress in both nuclear and mitochondrial DNA. This is supposed to lead to a series of pathological consequences [16]. Apart from energetic alterations imposed by oxidised bases with respect to intra- and inter-strand stacking interactions, there are also changes observed in hydrogen bonding patterns. The main consequence of nucleobase oxidation is the alteration of their donor-acceptor properties directly affecting coding abilities. For example, if guanine molecule undergoes oxidation the 8-oxoguanine can be

Table 1. Examples of cancer and non-cancer diseases, for which elevated levels of hydroxyl radical nucleobases were reported [12-15]. For notation of oxidative products see text in the introduction

\begin{tabular}{|c|c|}
\hline Cancer diseases & Elevated level in chromatin hydrolysates \\
\hline Acute lymphoblastic leukaemia (ALL) & $\mathrm{AA}, \mathrm{AB}, \mathrm{CA}$ \\
\hline Invasive ductal carcinoma & $\mathrm{AB}, \mathrm{GA}, \mathrm{GC}$ \\
\hline Squamous cell carcinoma (SCC) & $\mathrm{AA}, \mathrm{AB}, \mathrm{AC}$ \\
\hline Fibrillary astrocytoma (FA, brain) & $\mathrm{AA}, \mathrm{AB}, \mathrm{AC} \mathrm{UB}, \mathrm{GA}, \mathrm{GC}$ \\
\hline Lung cancer (LC) & $\mathrm{AA}, \mathrm{AB}, \mathrm{AC}, \mathrm{CA}, \mathrm{UB}, \mathrm{GA}, \mathrm{GB}, \mathrm{GC}$ \\
\hline Mucinous carcinoma (MC, stomach) & AA, AB, GA, GC, TA, UB \\
\hline Ovarian cancer $(\mathrm{OC})$ & $\mathrm{AA}, \mathrm{AB}, \mathrm{TA}, \mathrm{CA}, \mathrm{UB}, \mathrm{GA}, \mathrm{GB}$ \\
\hline Cockayne syndrome, prostatic carcinoma & $\mathrm{AB}$ \\
\hline Bladder cancer & $\mathrm{AB}, \mathrm{GA}, \mathrm{GC}, \mathrm{UB}, \mathrm{CA}$ \\
\hline $\begin{array}{l}\text { Bowen's disease, Cervical cancer, Colorectal cancer (CRC), Gastric adenocarcinoma, } \\
\text { Gynaecological cancers, Hepatocellular carcinoma (HCC) }\end{array}$ & GA \\
\hline Non-cancer disease & Elevated level in chromatin hydrolysates \\
\hline Huntington's disease (HD) & $\mathrm{AA}, \mathrm{AB}, \mathrm{AC}, \mathrm{GA}, \mathrm{GC}$ \\
\hline Dementia with Lewy bodies (DLB) & GA, GB, GC, CA, UC, TA \\
\hline HIV infection & GA, UC \\
\hline Diabetes mellitus type II & UC, TA, CA, GA, AA, AB, AC, GA \\
\hline Systemic lupus erythematosus (SLE) & GA, TA \\
\hline $\begin{array}{l}\text { Amyotrophic lateral sclerosis (ALS), Alzheimer's disease (AD), Parkinson's disease } \\
\text { (PD), Multiplex sclerosis (SM), Friedreich ataxia (FRDA), Haemochromatosis, } \\
\text { Chronic hepatitis, HCV, Cystic fibrosis (CF), Muscular dystrophy, Atopic dermatitis, } \\
\text { H. pylori infection, Chronic atrophic gastritis, Non-insulin-dependent (NIDDM), } \\
\text { Diabetes mellitus types I and II, Down's syndrome (DS), Fanconi's anemia }\end{array}$ & GA \\
\hline
\end{tabular}


formed. There is convincing evidence coming from both in vivo and in vitro experiments $[17,18]$ that GA can form pairs not only with canonical cytosine but also with adenine. Such mispairing can introduce error during the first replication round by incorporation of adenine opposite to 8-oxoguanine. Thus, during the second replication round the insertion of canonical thymine might take place and instead of original G-C pair the T-A transversion can occur. A similar mechanism also takes place if an oxidized nucleotide is present in the free nucleotide pool. In such a case the incorporation of non-canonical nucleotide can take place DNA forming non-standard pair from the scratch $[3,10,17]$. In cases when pyrimidine replaces purine or purine is incorporated instead of pyrimidine, such process is usually termed transversion. In situations of purine $\rightarrow$ purine or pyrimidine $\rightarrow$ pyrimidine replacement transition occurs. The accumulated knowledge of observed transitions and transversion grows rapidly, and reviewing this aspect, although fascinating and important, is beyond the scope of this paper. Rather, interests are focused on a chemical origin of the observed biological consequences of DNA oxidative damage. This intriguing aspect brought up increasing attention of many researchers in the decade [1969]. The first to use ab initio methods for characteristics of some selected tautomers of 8-oxoguanine were Aida and Nishimura [20]. Miaskiewicz et al [24, 25] studied thymine glycol and 5,6-dihydrothymine conformations by means of $a b$ initio and molecular dynamics simulations. First principle calculations were also applied for $\mathrm{pK}$ estimation of 8-oxoguanine and 5-substituted uracils [26-28]. The tautomerism of 2-hydroxyadenine known as isoguanine attracted attention since Rich and co-workers [29] demonstrated that this nucleobase was able to form a very stable complex with isocytosine [30-32]. Unique tautomeric properties of isoguanine were studied in the gas phase, in different pure solvents and inside B-DNA environment [33]. Also conformational aspects of modified nucleosides were the subject of a detailed analysis [19, 3442]. Cysewski at al. [43-69] studied different aspects of modified DNA bases including structural properties coming from tautomeric equilibriums, protonation/deprotonation abilities in polar and non-polar conditions, aromaticities, oxidative susceptibilities, N-glycosidic bond stabilities stacking interactions and also pairs formation via hydrogen bonding. Since these data were the subject of more than decade activities, they are dissipated between different sources. Besides, they were obtained on different levels according to available computer resources. Nowadays, standards offered by PSNC and also by other computational centres allow for application of up-to-date quantum chemistry levels. Also software packages now offer much more flexible and reliable theoretical tools than several years ago. Thus, a collection of data, bringing to the same level of theory and verification against available experimental data seem to be valuable and stand for the main purpose of this paper. Thus, a comprehensive discussion of the molecular alterations imposed by oxidative damage to nucleobases is presented in the forthcoming sections.

\section{METHOD OF CALCULATIONS}

Different levels of theory were applied for studying the molecular properties of heterocyclic compounds. They include semi-empirical, Hartree-Fock, different DFT implementations and even advanced levels including electron correlations. However, not all approaches are equally accurate [74-76]. Hence, all results reported here characterizing the tautomeric and protolytic properties of hydroxyl radical modified nucleobases were carefully studied on two levels. The structures of all possible tautomers were obtained based on B3LYP/aug-cc-pvDZ (aDZ) [70] gradient optimization followed by the Hessian estimation leading to thermodynamic data. Besides, G3 model chemistry method was applied, but only the most stable tautomers due to expenses of this approach. The relative percentage of tautomeric forms were estimated according to Boltzmann population based on Gibbs free energies in the gas phase and water solution. The influence of the solvation was estimated by the Polarizable Continuum Model (PCM) [71] with explicit hydrogen atoms and Bondi [72] parameterization. Since most estimated quantities were not experimentally measured for modified bases, each set of data was compared to available experimental data for canonical nucleobases. Due to significant structural similarities one can expect that applied methodology if reliable for trial heterocyclic compounds (DNA bases) will also be valid for tested ones (oxidized nucleobases analogues). If nucleosides were considered the simplified model was implemented, which instead of the whole 2'-deoxy-ribose ring, comprised only the methylmethoxy group $\left(-\mathrm{CH}_{2}-\mathrm{O}-\mathrm{CH}_{3}\right)$ mimicking the $\mathrm{N}$-glycosidic bond. Such model was documented as reliable [60-65] for it provides all important features of nucleosides with significant reduction of the size of the studied systems. The results of thermodynamic calculations were critically checked against imaginary frequencies ensuring that the obtained geometries correspond to global minima. Tight criterions were imposed for gradient minimization. Besides, the ultra fine option was used for a definition of 
grid mesh in DFT computations. All quantum chemistry calculations were performed with GAUSSIAN03 software package [73].

\section{RESULTS AND DISCUSSION}

Before characterizing the most important physicchemical properties of hydroxyl radical modified nucleobases or nucleosides, it is necessary to describe their structure controlled mainly by tautomeric equilibriums. In principle, a description of such equilibriums seems to be straightforward but the simplest methods are usually unsuitable [74-76]. Quantitative predictions of tautomers succession, relative stabilities energies or equilibrium constants require inclusion of higher electron correlation contributions and extended basis sets. It is rational to expect that canceling errors, typical for many chemical problem solved by quantum chemistry computations, allows for application of much less demanding levels. However, a quantitative analysis is necessary against available experimental data [77]. Thus, extensive calculations were performed for canonical nucleobases. For these compounds there are available experimental data corresponding to both gas phase and water solutions. Although relative energies of neutral and protonated nucleic acid bases were the subject of numerous studies and experimental values were consistently reproduced by $a b$ initio calculations [78], some additional notes are provided at this initial stage. Currently, the advanced $a b$ initio post-HF methods were successfully applied for identification of populations of neutral and protonated forms of DNA bases [78]. The correlation corrections up to MP4 were taken into account and the resulting values of proton affinities were within $2 \%$ of the experimental data. However, such challenging computations cannot be performed for the extended set of free radical derived analogues of nucleic acid bases. Fortunately, alternative and much less demanding level can be chosen [64]. As it was presented in our previous reports, both tautomeric equilibriums and protolytic properties are sensitive to both level of computations and the length of basis set expansions. The Hartree-Fock level was univocally dismissed since predictions based on this approach are significantly outside the experimental uncertainties [64, 65]. The application of such density functional method as B3LYP is quite reasonable, especially if extended basis sets were used. Unfortunately, non-monotonous correlation is observed between accuracy of GPB and the number of basis functions used. This is true for both split valence and correlation consistent basis sets [65]. It has been found that rational compromise between accuracy and computational costs is achieved if modest basis set aDZ is used along with the B3LYP method. In such a case the predicted values of gas phase basicities (GPB) were within $1.0 \mathrm{kcal} / \mathrm{mol}$ with respect to the experimental data. It is known that the values of macroscopic quantities as proton affinities [78] or gas phase basicities [64] depend mainly on the properties of the most probable tautomer. The inclusion in the analysis of the additional less stable tautomers usually does not alter the basicity of heterocyclic compounds. However, the characteristics of micro-basicities/acidities understood as the measure of the susceptibilities to protonation/deprotonation of individual proton-acceptor centers requires much higher precision since difference in the energies between some tautomers are often within $1 \mathrm{kcal} / \mathrm{mol}$. Such accuracy can be achieved using a more advanced level of computations. It has been found [64] that the model chemistry approach, G3MP2B3, is sufficient for prediction of experimentally observed succession of tautomers for both neutral and protonated species of nucleic acid bases. In cases where the B3LYP/aDZ and G3MP2B3 methods lead to contradictory predictions, the latter is suggested to be used in the interpretation of microscopic protonation properties. However, for the macroscopic GPB the accuracy of B3LYP/aDZ has been proven to be quite satisfactory. Thus, the results presented below are related to these two levels of calculations. An additional methodological problem arises if presence of solvent is considered. Despite enormous efforts in the formulation of the universal way of $\mathrm{pK}$ prediction from the first principles, at the current state of computational chemistry there is no univocal protocol offering accurate results independent of the nature of analysed class of compounds. Thus, before characterising the protolytic properties of hydroxyl radical analogues of nucleosides the verification of the methods was indispensable. Among many tested approaches the combination of the gas phase calculations described in the previous sections with PCM solvation model at the same level of theory (B3LYP/aDz) and Bondi radii [72] was found to be superior. Resulting $\mathrm{pK}$ values estimated for canonical nucleobases show linear relationship if plotted against experiential data. It has been found that such linear correlation holds both for $\mathrm{pK}$ values estimated with full geometry relaxation of solute in water conditions and also for solvation Gibbs free energies estimated using gas-phase geometries and only single point calculations in the presence of implicit water molecules. Interestingly, in both equations describing linear regression the slope is close to value 0.7 . And this value was arbitrarily used by Goddard III et al. [26-28] for scaling of raw pK data describing protolytic properties of guanine, 8-guanine and xanthine. 


\section{Tautomeric properties of modified nucleosides}

The typical feature of many heterocyclic compounds is potential existence as mixtures of many potential tautomeric isomers. This is also the case for nucleosides and their free radical analogues [43-60]. They can undergo reversible processes of migration of one or more double bonds and hydrogen atom(s) in so-called prototropic tautomerism [79, 80]. This mechanism leads to enol-keto and amino-imino isomers. There is also possible hydrogen migration between nitrogen centres constituting ring skeletons. Moreover, rotation of side groups attached to rings via single bond should also be taken into account and exceeds the number of potential structures.

Three products of hydroxyl radical degradation of adenosine were identified [1-3], namely 2-hydroxyade- nosine (AA), 8-oxoadenosine (AB) and fapy adenosine (AC). The analogue of adenosine that is oxidized at $\mathrm{C}_{2}$ position is also known in the literature as isoguanosine [33]. This compound is very sensitive to the polarity of the environment since isomers that are dominant in the gas phase are not necessarily the most probable ones in water solution. As it was presented in Fig. 1 AA adopts predominantly amino-enol form (AA1) in non-polar environment, while in the polar solution the keto-amino tautomer (AA2) is favoured [47, 48]. The former isomer as less polar and dominates in the vapour state while the latter due to its higher polarity predominates if water field is present. The enol-amino tautomer of AA has rotatable hydroxyl group attached to $\mathrm{C}_{2}$ centre and there are two preferential conformation coplanar with the purine ring skeleton. The<smiles>[R]n1c([2H])nc2c(N([2H])[2H])nc(O)nc21</smiles><smiles>[R]n1c([2H])nc2c(N([2H])[2H])n([2H])c(=O)nc21</smiles><smiles>[R]n1c(=O)n([2H])c2c(N)nc([2H])nc21</smiles>

AA1 $(61.8 \%, 67.3 \%, \mathbf{0 . 0} \%)$

$\operatorname{AA2}(0.0 \%, 0.1 \%, \mathbf{1 0 0 . 0} \%)$

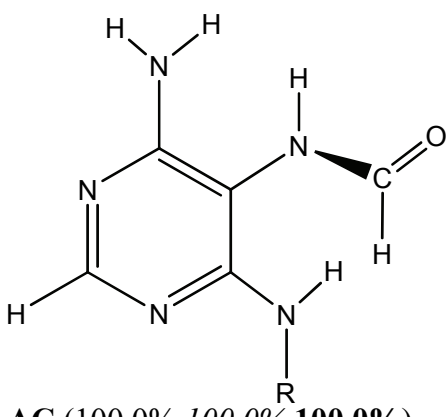<smiles>[R]n1c(=O)n([2H])c2c(=O)[nH]c(N)nc21</smiles>

AB $(100.0 \%, 100.0 \%, \mathbf{1 0 0 . 0} \%)$

$\mathrm{AC}(100.0 \%, 100.0 \%, \mathbf{1 0 0 . 0} \%)$

GA1 $(33.8 \%, 74.9 \%, \mathbf{1 0 0 . 0} \%)$<smiles>[R]n1c(=O)n([2H])c2c(O[2H])nc(N)nc21</smiles><smiles>[R]n1c([2H])nc2c(=O)[nH]c(=O)[nH]c21</smiles>

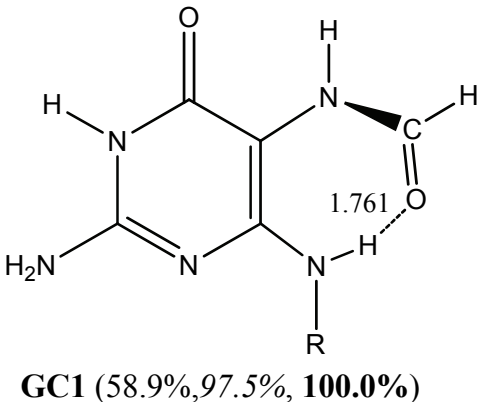

GA2 $(66.2 \%, 25.1 \%, \mathbf{0 . 0} \%)$

GC1 $(58.9 \%, 97.5 \%, \mathbf{1 0 0 . 0} \%)$

Fig. 1. Tautomeric properties of hydroxyl radical modified model adenosine. Only most probable isomers are included. Symbol $\mathrm{R}$ denotes methylmetoxy group mimicking the 2'-deoxiribose sugar backbone. Percentages presented in normal face and italics correspond to the gas phase Boltzmann populations estimated by G3MP2B3 and B3LYP/aDZ methods, respectively. Bold style denotes populations resulting from solvation Gibbs free energies that were estimated based on gas-phase geometry using PCM//B3LYP/aDZ method with Bondi parameterisation 
summed percentage of resulting conformers reach in total $100 \%$. The difference between these rotamers is small and equals about $0.4 \mathrm{kcal} / \mathrm{mol}$. Next two adenosine analogues, $\mathrm{AB}$ and $\mathrm{AC}$, have very simple tautomeric properties. For both of these derivatives only one form is expected in polar and non-polar conditions, namely the amino-keto isomer of 8-oxo-adenosine (AB) and fapy-adenosine (AC) are dominant tautomers irrespectively of the polarity of the environment. It is worth mentioning that $\mathrm{AC}$ is not flat since the value of $\mathrm{C}_{6}-\mathrm{C}_{5}-\mathrm{N}_{7}-\mathrm{C}_{8}$ dihedral angle is equal to $95.5^{\circ}$ and $94.8^{\circ}$ in vapour and water, respectively. In the case of adenosine derivatives there are no contradictory predictions of tautomers succession concluded based on both B3LYP and G3MP2B3 methods.

Canonical guanosine can also undergo oxidation, which leads to the following derivatives: 8-oxoguanosine (GA), xanthosine (GB) and fapy guanisine (GC). The first of these analogues is the most abundant derivative of oxidative stress [1-3] and for this reason is used as a marker for prediction of cancer developments $[10,16]$. As it is demonstrated in Fig. 1 the 6,8-diketo form (GA1) is dominant in water solution [54]. In non-polar conditions the 6-enol-8-keto isomer (GA2) can also be present but prediction of the relative populations in the gas phase of these two isomers is opposite if the B3LYP and G3MP2B3 methods are considered. The former approach suggests that 6,8-diketo form is dominant, while the model chemistry treatment points on 6-enol-8-keto isomer as principal one in the gas phase. Since the environment polarity significantly reduces the population of this tautomeric form in water polar solution the diketo-form is predominant [19, 26, 34-36]. The 8-oxoguanine is an example of compound which breaks the rule relating the population of tautomeric form with its dipole moment. The GA1 tautomer is more polar both in the gas phase and in water solution than GA2 isomer. Xanthosine (GB) exists predominantly as 2,6-diketo form irrespectively of the environment polarity [26, 62]. Fapy guanosine (AC) adopts predominantly the ketoamino form (GC1) in both gas phase and water solution. However, a small amount of the enol-amino form is to be expected in the non-polar gas phase. Interestingly, both tautomers are characterised by almost the same values of dipole moment in the gas phase. In polar condition polarity of GC1 becomes slightly higher. There is important structural difference between fapy adenosine and fapy guanosine. The latter is much more flat and the value of $\mathrm{C}_{6}-\mathrm{C}_{5}-\mathrm{N}_{7}-\mathrm{C}_{8}$ dihedral angle is much higher for $\mathrm{GC}$ if compared to $\mathrm{AC}$ and is equal to $155.3^{\circ}$ and $134.1^{\circ}$ in gas vapour and water, respectively. Thus, it is expected that the presence of fapy guanine in double stranded DNA will results in much smaller structural and energetic distortions than imposed by fapy adenosine.

The interactions of hydroxyl radical with cytosine lead to the following five derivatives, 5-hydroxycytidine (CA), cytidine glycol (CB), 5,6-dihydroxycytidine (CC), 6-hydroxy5,6-dihydrocytidine (CD), 5-hydroxy-5,6-dihydrocytidine (CE). Tautomeric equilibriums are quite complex as it was presented in Fig. 2. For example, 5-hydroxycytidine (CA) may exists in the vapour state as a mixture of keto-amino (CA1) and keto-imino (CA2) tautomers. The most stable in vapour state is the former isomer with hydroxyl group coplanar with ring moiety. Both applied methods, B3LYP/aDZ and G3MP2B3, lead to the same predictions, but the latter slightly favours the most probable isomer (CA2(1a)). On the contrary, the keto-amino form is predominant in the polar solution. Interestingly, the dipole moment of the most abundant keto-imino tautomer is much smaller than for keto-amino isomer. In the case of this derivative spectacular influence of the solvent polarities on tautomers succession is observed. As it was previously documented [52], the inversion of the relative stability of the studied tautomer is expected not only in water but also in acetone and cyclohexane. The more polar solvent, the more stable the amino-keto tautomer. The next analogue of cytidine is the cytidine glycol (CB). The structure of this derivative is significantly affected by oxidation, since the double bond between $\mathrm{C}_{5}$ and $\mathrm{C}_{6}$ atoms no longer exists. This results in significant non-planarity of this derivative. A flat pyrimidine plane in the case of cytidine becomes chair-like for cytidine glycol tautomers. Two existing chiral centres on $\mathrm{C}_{5}$ and $\mathrm{C}_{6}$ atoms extend a structural diversity of cytidine glycol. There are potential four diastereoisomers for each tautomeric form. However, due to the ring inversion, each of the stereoisomers can exist in two equatorial-axial conformations [53]. In a uniform environments, the existing eight optical conformers form four pairs of enantiomers. Thus, one has to consider only four unique diastereoisomers of cytosine glycol tautomers. All distinct conformers corresponding to $\mathrm{SS}\left(\mathrm{C}_{5} \mathrm{axC}_{6} \mathrm{ax}\right), \mathrm{SR}\left(\mathrm{C}_{5} \mathrm{axC} \mathrm{C}_{6} \mathrm{eq}\right)$, $\mathrm{RS}\left(\mathrm{C}_{5}\right.$ eq $\left.\mathrm{C}_{6} \mathrm{ax}\right)$ and $\mathrm{RR}\left(\mathrm{C}_{5}\right.$ eqC $\mathrm{C}_{6}$ eq $)$ were the subject of a detailed analysis. It is noteworthy, however, that in an asymmetric environment (deoxyribose moiety, DNA interior, solvent molecules, metal ions, ligands, etc.) energetic degeneracy of these enantiomers can be destroyed and energetic degeneracy may disappear. As it was previously reported [62], not all stereoisomers are equally probable. The results presented in Fig. 2 suggest that equatorial conformation of $\mathrm{C}_{5}$ centre and axial conformation of $\mathrm{C}_{6}$ atom are dominant irrespectively of the tautomeric form and polarity of the environment. Among 
all possible stereo-isomers and tautomers CB1(5eq, 6ax) form was found as the most probable one. Although both applied methods point to this isomer as the most probable one, the model chemistry suggests much higher percentage of this isomer in the total population. However, the exchange of the succession of keto-amino (CB2) and keto- imino (CB1) tautomers is expected after immersion in the polar medium. In water field the more polar isomer CB2 is dominant, while in vapour state dominates the CB1 tautomer. The third studied analogue of cytidine is 5,6-dihydroxy derivative (CC). Although the keto-amino tautomer, $\mathrm{CC} 2$ (bd), has been identified as the most stable among<smiles>[R]n1c([2H])c(OC)c(N([2H])[2H])nc1=O</smiles>

CA1

$(2.2 \%, 16.5 \%, \mathbf{1 0 0 . 0} \%)$

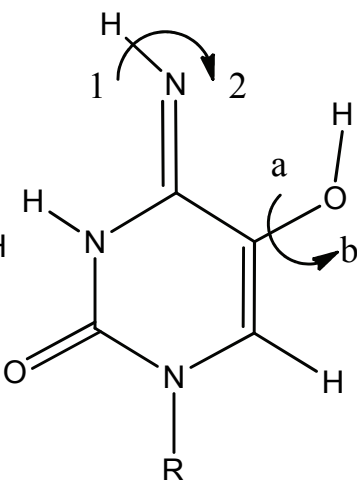

CA2(1a)

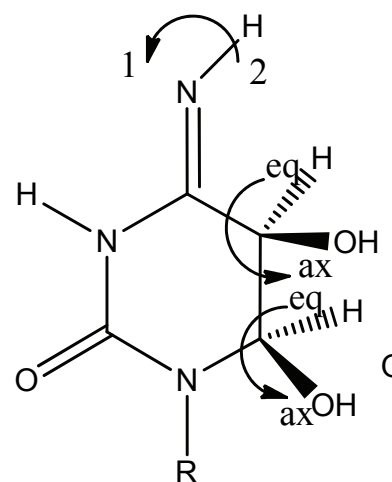

CB1(2,5eq,6ax) $(88.8 \%, 63.1 \%, \mathbf{0 . 1 \%})$<smiles>[R]N1C(=O)N=C(N([2H])[2H])[C@H](O)[C@]1([2H])O</smiles>

CB2(5eq,6ax)

$(0.5 \%, 4.0 \%, 99.9 \%)$

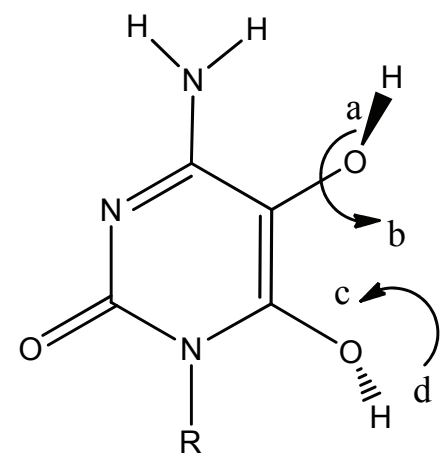

CC1(ac) ( 5.4\%, 2.4\%,94.1\%)

CC1(bd) $(63.0 \%, 95.2 \%, \quad 5.9 \%)$<smiles>[R]N1C(=O)N=C(N([2H])[2H])C[C@@]1(CO)C(Cl)Cl</smiles>

CD2(ax)

$(0.2 \%, 1.4 \%, 99.9 \%)$

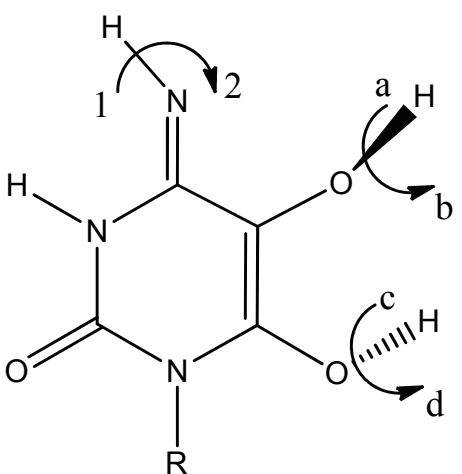

CC2 $(1, \mathrm{ac})$

$(30.7 \%, 2.4 \%, \mathbf{0 . 0} \%)$

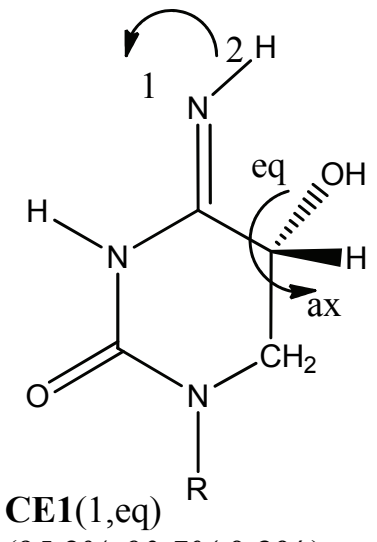

$(95.2 \%, 93.7 \%, \mathbf{0 . 3 \%})$<smiles>[Y]CCI</smiles>

CD1 $(2$, ax $)$

$(99.7 \%, 98.3 \%, \mathbf{0 . 0} \%)$

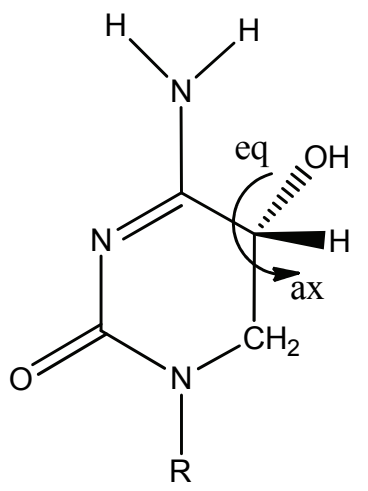

CE2(eq)

$(0.0 \%, 0.0 \%, 99.0 \%)$

Fig. 2. Tautomeric properties of hydroxyl radical modified model cytidine. Notation is the same as in Fig. 1 
all potential isomers, also keto-imino tautomer, $\mathrm{CC} 4(1, \mathrm{ac})$, can occur in the population of neutral forms. Two hydroxyl groups attached to $\mathrm{C}_{5}$ and $\mathrm{C}_{6}$ atoms can rotate and two energetic minima were located for either tautomeric form. The oxidation of cytidine both in aerobic and anaerobic conditions can also yield 6-hydroxy-5,6-dihydrocytidine (CD). Attachment of the hydroxyl group to $\mathrm{C}_{6}$ atom results in stereoisomers as it was demonstrated in Fig. 2. Thus, each of the tautomers may be characterised by $\mathrm{S}$ or $\mathrm{R}$ conformation of the $\mathrm{C}_{6}$ chiral atom. Due to the ring inversion there are two axial-equatorial orientations of the hydroxyl group. Assuming uniform environment there are only two distinct enantiomers, namely $\mathrm{S}\left(\mathrm{C}_{6} \mathrm{ax}\right)$ and $\mathrm{R}\left(\mathrm{C}_{6} \mathrm{eq}\right)$. In the gas phase the keto-imino tautomer (CD2) precedes keto-amino one (CD1). In water solution the succession of these tautomeric forms is reversed. The environment does not change the chirality of $\mathrm{C}_{6}$ centre since axial conformation is energetically more favourable than equatorial one. Imino tautomer of 6-hydroxy-5,6dihydrocytidine $\mathrm{CD} 1(\mathrm{ax})$ is more polar than $\mathrm{CD} 2(\mathrm{ax})$ both in water and vapour. The last cytidine analogue studied here, 5-hydroxy-5,6-dihydrocytidine (dCE), has very simple tautomeric features. This derivative has one chiral centre, located on $\mathrm{C}_{5}$ atom. Among all potential conformations the equatorial configuration is most favoured independently of the polarity of the environment. In the gas phase the keto-amino isomer denoted as $\operatorname{CE} 1(1$, eq) is dominant. Although keto-amino form, CE2(eq), is very improbable in the vapour state it is dominant in water solution.

Thymidine and uridine analogues isolated in chromatin hydrolysates have simple tautomeric properties. As it is documented in Fig. 3 and 4, all derivatives exist exclusively in 2,4-diketo forms [62] irrespectively of the environmental polarity. Although, some of these compounds may exist as a mixture of different isomers, but their structures result from either chirality conformations or side group rotation rather than from tautomeric equilibriums. These potential isomers were described in Fig. 3 and 4. One centre of chirality is present in the case of 5-hydroxy-5,6-dihydrothymidine (TC), 5,6-dihydrothymidine (TD), isodialuric acid (UA) and 5-hydroxy-5,6-dihydrouridine (UD), while two assymetric carbon atoms are present in thymidine glycol (TB), 6-hydroxy-5,6-dihydrothymidine (TE) and uridine glycol (UE).<smiles>[R]n1cc(CO)c(=O)[nH]c1=O</smiles>

TA $(100.0 \%, 100 \%, \mathbf{1 0 0} \%)$

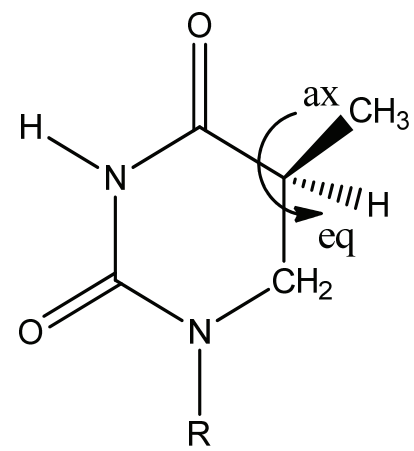

$\operatorname{TD}(5$ eq $)(75.8 \%, 85.0 \%, 89.0 \%)$

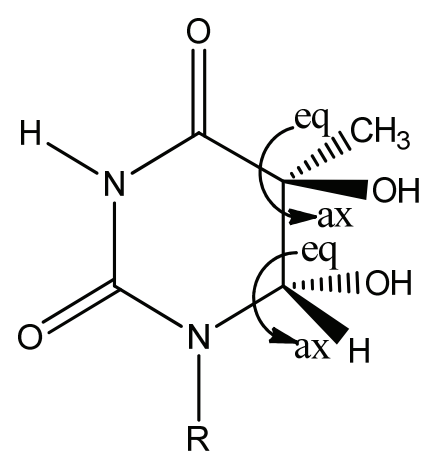

TB(5eq,6ax) (97.8\%,98.2\%,79.7\%)

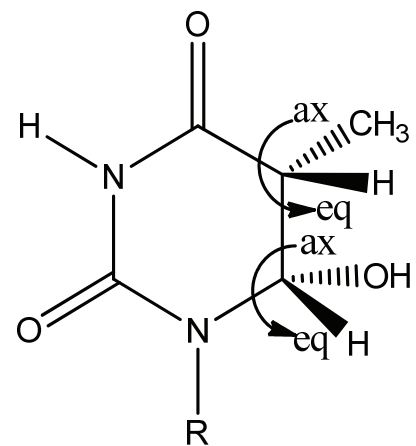

TE(5eq,6eq) $(54.1 \%, 54.7 \%, \mathbf{6 5 . 0} \%)$

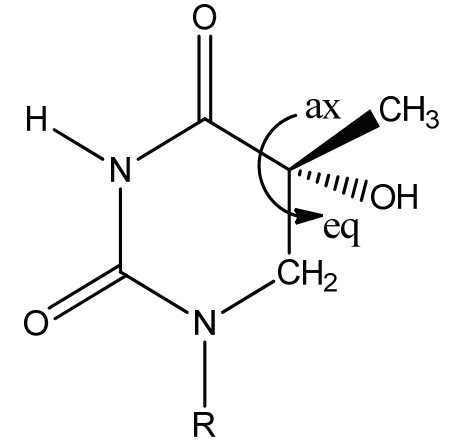

TC(5ax) $(97.5 \%, 94.0 \%, 51.9 \%)$

TF(b) $(99.9 \%, 99.9 \%, \mathbf{4 2 . 4 \%})$

Fig. 3. Tautomeric properties of hydroxyl radical modified model thymidine. Notation is the same as in Fig. 1 
<smiles>[R]N1C(=O)NC(=O)C(=O)[C@@]1([Y])O</smiles>

$\mathbf{U A}($ eq $)(6.2 \%, 16.6 \%, \mathbf{8 9 . 4 \%})$

UA(ax) $(93.8 \%, 83.4 \%, \mathbf{1 0 . 6 \%})$

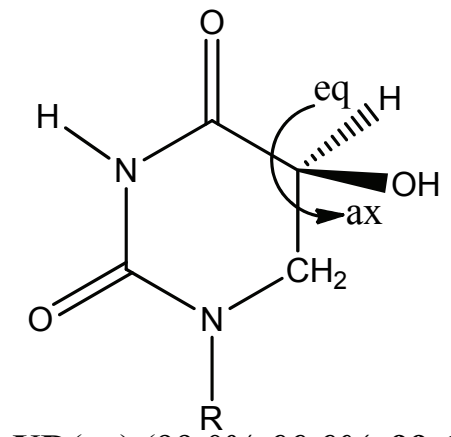<smiles>[R]n1c(O)c(O)c(=O)[nH]c1=O</smiles>

UB $(100.0 \% 100.0 \%, \mathbf{1 0 0 . 0} \%)$

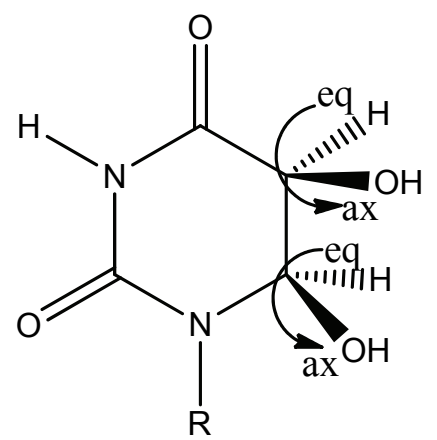

UE(5eq,6eq) $(94.9 \%, 97.2 \%, \mathbf{8 8 . 6 \%})$<smiles>[R]N1C(=O)N([2H])C(=O)C(O[2H])C1[2H]</smiles>

UC $(100.0 \%, 100.0 \%, \mathbf{1 0 0 . 0} \%)$

$\mathbf{U D}($ eq) $(99.0 \%, 99.9 \%, \mathbf{9 9 . 6 \%})$

Fig. 4. Tautomeric properties of hydroxyl radical modified model uridine. Notation is the same as in Fig. 1

The above discussion emphasised that structural properties of free radical modified nucleobases are quite complex and they cannot be directly derived from chemical formula, especially that polarity of the environment can profoundly affect tautomeric equilibriums. Thus, the computational efforts clarified which structures to be considered as dominant. Some isomers come from tautomeric equilibriums, some are related to other structural features as a rotation of the side groups or chirality of asymmetric centres. Since most of hydroxyl radical analogues are poorly soluble in water the experimental data characterising structure of analysed class of heterocyclic compounds are not available. Thus, this is quantum chemistry approach that offer deeper insight into structural details of hydroxyl radical modified nucleobases. The knowledge of structure is indispensable for assessment of many physic-chemical properties as protonation/deprotonation equilibriums including $\mathrm{pK}_{\mathrm{a}}$ values, oxidative susceptibilities, $\mathrm{N}$-glycosidic bond stabilities and, what is most important, also H-bonded pairs formation, which directly affects their coding abilities. All these aspects will be discussed in the forthcoming sections.

\section{Gas phase basicities}

The ability to participate in protolytic equilibriums is an important factor characterizing the functionality of heterocyclic compounds [81-83]. Basicity and acidity affects such phenomena as self-association, base-pairing, interaction with metal ions and amino acids both in vivo and in vitro. For example, cytosine protonated at the $\mathrm{O}_{2}$-oxygen is expected to be responsible for the stabilization of adeninecytosine mispair that was observed in single crystals of oligonucleotide duplexes [82]. There are two interplaying processes defining protolytic features. First of all, the tautomeric equilibriums determine type and amount of protonacceptor and proton-donor centres. Additionally, acidity of the environment forces the ratio of neutral and ionic forms. The gas phase basicity (GPB) is a macroscopic property directly related to Gibbs free energy of protonation reaction. However, in case of heterocyclic compounds many potential tautomers of both neutral and protonated forms can be involved in the equilibrium. Methodology described elsewhere [64, 68] utilizes Boltzmann probabilities of specific N-site-protonation. Thus, simple estimation of Gibbs free energies of all possible neutral and protonated tautomers 
that can potentially be present in the gas phase is sufficient for both macroscopic and microscopic prototropic features.

Protonation of model 2-OH-adenosine leads mainly proton attachment to amino-keto tautomer at $\mathrm{N}_{3}$ centre (see Fig. 1). Slightly less probable is the form corresponding to isomer with proton added to $\mathrm{N}_{3}$ atom of AAla tautomer. Hence, for 2-hydroxyadenosine the $\mathrm{N}_{3}$ nitrogen atom has the most basic character. Basicity of $\mathrm{N}_{1}$ atom is much less pronounced. This observation suggests that oxidation does not alter the micro-basicities with respect of canonical adenosine. Thus, despite the presence of hydroxyl group attached to $\mathrm{C}_{2}$ atom no changes in succession of basicities of $\mathrm{N}_{1}$ and $\mathrm{N}_{3}$ centers are observed. The same conclusion may be drawn taking into account the results for 8-oxoadenosine and fapy-adenosine $[62,63]$ since protonation takes place predominantly at $\mathrm{N}_{3}$ position. The gas phase basicities of adenosine analogues were presented in Table 2. The value of GPB corresponding to model adenosine estimated on the same level (B3LYP/aDZ) is equal to $221.3 \mathrm{kcal} / \mathrm{mol}$ [64]. Comparison of data collected in Table 2 lead to the conclusion that model fapy-adenosine and 2-OH-adenosine are more basic compared to nonmodified model adenosine. To the contrary, the model 8oxoadenosine is less basic compared to non-oxidized adenosine. Thus, noteworthy impact of the oxidation on the basicities of modified adenosines is observed and in the case of $\mathrm{AC}$ it is equal to $+4.1 \mathrm{kcal} / \mathrm{mol}$, for $\mathrm{AA}$ is about $+2.4 \mathrm{kcal} / \mathrm{mol}$ and for $\mathrm{AB}$ equals $-2.0 \mathrm{kcal} / \mathrm{mol}$. In either case $\mathrm{N}_{3}$ atom is the most basic centre, the same as for nonmodified adenosine. The most probable protonated form 8-oxoguanosine is GA2 isomer with proton attached to $\mathrm{N}_{3}$ centre. This observation disagrees with findings of Jang et al. [26] that $\mathrm{N}_{1}$ deprotonated cationic form is to be most probable. However, in their study modified nucleobase was used rather than nucleoside deficient from $\mathrm{N}_{9}$ hydrogen atom. The presence of oxygen atom in methylmethoxy group stabilizes this tautomer by interaction of $\mathrm{H}_{3}$ atom with oxygen of $-\mathrm{CH}_{2} \mathrm{OCH}_{3}$ exocyclic group. This mimics potential base-sugar interaction in nucleosides, which as in this case, can play a stabilizing role. The next tautomer of protonated 8-oxoguanosine is the addition of proton to $\mathrm{N}_{3}$ heteroatom of 6,8-diketo form. Thus, $\mathrm{N}_{3}$ centre can be treated as the most basic one in the case of most stable 8 -oxoguanosine tautomers. In case of model xanthosine (GB) $\mathrm{N}_{7}$ centre stands for most basic one both for 2,6diketo and 2-enol-6-keto tautomers. However, there is disagreement in abundances of most stable tautomers if results coming from 3LYP and G3 methods are compared since model chemistry approach predicts that the latter isomer is most abundant while the conclusion drawn from DFT calculations is opposite.

As it was previously mentioned, there are at least five known cytidine analogues imposed by the reactive oxygen forms. All these analogues posses complex tautomeric equilibriums in protonated forms. Details characterising macro- and microbasicites are collected in Table 2. Proto-

Table 2. The gas phase macro- and micro-basicities (GPB) (in $\mathrm{kcal} / \mathrm{mol}$ ) of canonical and hydroxyl radical modified model purine and pyrimidine nucleosides. Numbers in bolt style come from G3MP2B3 computations

\begin{tabular}{|c|c|c|c|c|c|}
\hline & $\begin{array}{l}\text { Macroscopic } \\
\text { basicities }\end{array}$ & $\begin{array}{l}\text { Microscopic } \\
\text { basicities }\end{array}$ & & $\begin{array}{l}\text { Macroscopic } \\
\text { basicities }\end{array}$ & $\begin{array}{l}\text { Microscopic } \\
\text { basicities }\end{array}$ \\
\hline $\mathbf{A A}$ & 223.7 (222.8) & $\mathrm{N}_{3}(\mathbf{2 3 5 . 4})>\mathrm{N}_{7}(\mathbf{2 3 2 . 2})$ & dTA & 204.5 (205.1) & $\mathrm{O}_{4}\left(\right.$ 203.6) $>\mathrm{O}_{2}($ 198.9) \\
\hline $\mathbf{A B}$ & 219.3 (218.3) & $\mathrm{N}_{3}(218.3)>\mathrm{N}_{1}(213.7)$ & dTB & 201.4 (201.8) & $\mathrm{O}_{2}(\mathbf{2 0 1 . 7})>\mathrm{O}_{4}(\mathbf{1 9 4 . 0})$ \\
\hline $\mathbf{A C}$ & 225.4 (225.1) & $\mathrm{N}_{3}(225.1)>\mathrm{N}_{1}(217.5)$ & dTC & 204.5 (205.0) & $\mathrm{O}_{2}(\mathbf{2 0 5 . 0})>\mathrm{O}_{4}(\mathbf{1 9 3 . 1})$ \\
\hline $\mathbf{A}$ & $221.3(\mathbf{2 2 1 . 3 )}$ & $\mathrm{N}_{3}(\mathbf{2 2 1 . 2})>\mathrm{N}_{1}(\mathbf{2 2 0 . 1})$ & dTD & 204.7 (205.1) & $\mathrm{O}_{2}(\mathbf{2 0 4 . 3})>\mathrm{O}_{4}(\mathbf{1 9 7 . 2})$ \\
\hline GA & 214.9 (213.6) & $\mathrm{N}_{3}\left(\right.$ 213.8) $>\mathrm{N}_{1}(\mathbf{2 1 0 . 7})$ & dTE & 201.7 (201.7) & $\mathrm{O}_{2}(\mathbf{2 0 1 . 8})>\mathrm{O}_{4}(\mathbf{1 9 6 . 1})$ \\
\hline GB & $217.2(\mathbf{2 1 8 . 0})$ & $\mathrm{N}_{7}(218.0)>\mathrm{N}_{3}(201.5)$ & dTF & 206.3 (206.8) & $\mathrm{O}_{4}(\mathbf{2 0 6 . 6}) \approx \mathrm{O}_{5}(\mathbf{2 0 6 . 0})$ \\
\hline GC & $223.6(\mathbf{2 2 4 . 2})$ & $\mathrm{N}_{3}(\mathbf{2 2 4 . 5})$ & dT & 206.6 (207.2) & $\mathrm{O}_{2}(\mathbf{2 0 7 . 2})>\mathrm{O}_{4}(\mathbf{2 0 5 . 0})$ \\
\hline $\mathbf{G}$ & 226.4 (225.1) & $\mathrm{N}_{7}(225.1)>\mathrm{N}_{3}(220.2)$ & dUA & 194.3 (194.1) & $\mathrm{O}_{2}(\mathbf{1 9 5 . 5})>\mathrm{O}_{4}(\mathbf{1 8 9 . 6})$ \\
\hline $\mathbf{C A}$ & 224.8 (225.0) & $\mathrm{O}_{2}(\mathbf{2 2 7 . 2})>\mathrm{N}_{4}(\mathbf{2 2 1 . 9})$ & dUB & 202.4 (202.5) & $\mathrm{O}_{4}(\mathbf{2 0 2 . 4})>\mathrm{O}_{2}(\mathbf{2 0 0 . 6})$ \\
\hline CB & 220.9 (220.2) & $\mathrm{N}_{3}(223.3)>\mathrm{O}_{2}(221.3)$ & dUC & 200.7 (201.1) & $\mathrm{O}_{4}(\mathbf{2 0 0 . 7}) \approx \mathrm{O}_{2}(\mathbf{2 0 0 . 0})$ \\
\hline $\mathrm{CC}$ & 227.4 (226.6) & $\mathrm{N}_{3}(\mathbf{2 2 8 . 1})>\mathrm{O}_{2}(\mathbf{2 2 6 . 0})$ & dUD & 201.8 (202.9) & $\mathrm{O}_{2}(\mathbf{2 0 1 . 4})>\mathrm{O}_{4}(\mathbf{1 9 5 . 8})$ \\
\hline CD & $222.0(\mathbf{2 2 1 . 2})$ & $\mathrm{N}_{3}(224.7)>\mathrm{O}_{2}(223.7)$ & dUE & $199.9(\mathbf{2 0 0 . 5 )}$ & $\mathrm{O}_{2}(\mathbf{2 0 0 . 5})>\mathrm{O}_{4}(\mathbf{1 9 2 . 4})$ \\
\hline $\mathbf{C E}$ & $220.0(\mathbf{2 1 9 . 0})$ & $\mathrm{O}_{2}(\mathbf{2 2 3 . 2})>\mathrm{N}_{4}(\mathbf{2 1 9 . 0})$ & dU & 204.7 (205.1) & $\mathrm{O}_{2}(\mathbf{2 0 5 . 1})>\mathrm{O}_{4}(\mathbf{2 0 3 . 8})$ \\
\hline $\mathbf{C}$ & 224.6 (224.9) & $\mathrm{O}_{2}\left(\right.$ 224.6) $\approx \mathrm{N}_{3}($ 224.2) & & & \\
\hline
\end{tabular}


nation of 5-hydroxycytidine leads only to amino forms and the predominant isomer of cationic 5-hydroxycytidine adopts the enol-amino structure. The values of the gas phase basicity presented in Table 2 allow concluding that the modification of 5-hydroxycytidine has only minor impact on the macroscopic measure of basicity. However, the microscopic properties, describing basicities of particular proton-acceptor centre are altered if compared to model cytidine. The canonical cytidine grants its basic character from $\mathrm{N}_{3}$ and $\mathrm{O}_{2}$ centres and both these sites posses almost identical basicities. In the case of 5-hydroxycytidine the same atoms are involved in the protonation process and additionally, the $\mathrm{N}_{4}$ centre of imino tautomers may be susceptible to proton attachment. The most basic character exhibits $\mathrm{O}_{2}$ centre and both nitrogen atoms are slightly less basic (see Table 2). Thus, although the GPB of canonical cytosine and CA are almost the same, the micro-basicities are affected by oxidation of cytidine at $\mathrm{C}_{3}$-centre and increase is observed in basicity of $\mathrm{O}_{2}$ atom for CA compared to canonical cytidine. The products of $\mathrm{CB}$ protonation can adopt numerous tautomers and diastereoisomers but two are predominant in the whole population. The product of protonation of keto-imino tautomer at $\mathrm{N}_{4}$ centre was found as the most probable. From the structural point of view, it is identical to product of proton attachment to $\mathrm{N}_{3}$ nitrogen atom of amino-keto form. The cytidine glycol is less basic than canonical cytidine by about $5 \mathrm{kcal} / \mathrm{mol}$. The micro-basicities provided in Table 2 suggest that $\mathrm{N}_{3}$ atom is the most basic one in the case of cytidine glycol but still less basic then $\mathrm{O}_{2}$ centre of cytidine. Thus, both macro- and micro- basicities of CB are lower than for cytidine. There are three potential basicity centres of 5,6-dihydroxy derivative (CC) that can undergo protonation. As it was presented in the Table 2, the $\mathrm{N}_{3}$ atom is responsible for the most basic character of this derivative. Interestingly, $\mathrm{CC}$ is more basic compared to cytidine both from the macroscopic and microscopic point of views and even the least basic atom $\mathrm{N}_{4}$ is as basic as the $\mathrm{O}_{2}$ centre of cytidine. The fourth analyzed here product of cytidine oxidation, 6-hydroxy-5,6-dihydrocytidine (CD), is $3 \mathrm{kcal} / \mathrm{mol}$ weaker base compared cytidine by if the macroscopic measure of basicity is considered. The most basic sites of $\mathrm{CD}$ and $\mathrm{C}$ are equally susceptible to proton attachment an microbasicities are similar. Finally the last studied here cytidine analogue, 5-hydroxy-5,6-dihydrocytidine (CE), has very simple prototropic features. Due to the fact that the $\mathrm{N}_{3}$ centre of this tautomer is capped by hydrogen atom this site cannot serve as proton acceptor and only two centres are available for protonation, namely $\mathrm{O}_{2}$ and $\mathrm{N}_{4}$. There is strong difference between basicities of these two atoms and although the former has much higher affinity toward protonation the resulting cationic form CE2(eq) is energetically disfavoured. Thus, the overall basic character of $\mathrm{CE}$ is granted from basicity of $\mathrm{N}_{4}$ centre. This derivative is supposed to be the least basic among all studied here cytidines, including canonical one.

The basic character of canonical thymidine is about $19 \mathrm{kcal} / \mathrm{mol}$ lower in comparison to cytidine. Consequently, all studied here thymidine analogues are also very weak bases and in all cases the oxidation even reduces the basic nature of resulting compounds as is it documented in Table 2. For example, the only stable tautomer of 5-hydroxy-methyluridine (TA) adopts the diketo-form and may be protonated only at $\mathrm{O}_{2}$ or $\mathrm{O}_{4}$ centres. Protonation of TA leads either to 2-keto-4-enol or 2,4-dienol cations with most abundant population of the latter one in the gas phase. The thymidine itself has also the same proton acceptor centres but $\mathrm{O}_{2}$ site is about $2 \mathrm{kcal} / \mathrm{mol}$ more basic than $\mathrm{O}_{4}$ atom. However, in the case of 5-hydroxy-methyluridine the order of the micro-basicities is reversed. Nevertheless, both macro- and micro-basicities are lower for TA compared to canonical thymidine. The succession of $\mathrm{O}_{2}$ and $\mathrm{O}_{4}$ basicities of protonated thymidine glycol $(\mathrm{TB}(5 \mathrm{eq}, 6 \mathrm{ax}))$ is the same as for non-modified model thymidine. Similar conclusion may be drawn for next three derivatives, namely 5-hydroxy-5,6-dihydrothymidine (TC), 5,6-dihydrothymidine (TD) and 6-hydroxy-5,6-dihydrothymidine (TE). In the case of $\mathrm{TC}$, the protonation at $\mathrm{N}_{3}$ site leads to promotion of equatorial conformation of $\mathrm{C}_{5}$ atom. This is the only case among all studied derivatives for which protonation is accomplished with changes of the centre chirality. The last thymidine analogue has interesting protonation abilities. In the neutral form, there is possible free rotation of the formyl group bound to $\mathrm{C}_{5}$ carbon atom. However, after protonation, the site group is fixed in syn orientation with respect of $\mathrm{O}_{4}$ atom. This allows for hydrogen attachment in two ways either on $\mathrm{O}_{4}$ or $\mathrm{O}_{5}$ basic centres. In whichever case, there is formed very strong and short intra-molecular hydrogen bond. The basic characters of $\mathrm{O}_{4}$ site is slightly stronger than of $\mathrm{O}_{5}$ centre and much stronger compared to $\mathrm{O}_{2}$ oxygen atom. Basicity of 5-formyluridine is almost the same as canonical thymidine if macroscopic GPB is taken into account.

\section{Gas phase acidities}

All analyzed heterocyclic compounds can potentially manifest its acidic character by dissociation of proton from one of heteroatoms. Although purine and pyrimidine are all termed nucleic acid bases obviously this is much more correct in relation to adenine, guanine and cytosine, but much less appropriate in context of thymidine and uracil. The values of Gibbs free energies of deprotonation reaction 
are provided in Table 3. Among all non-modified nucleosides the most acidic seems to be guanosine, and the least

Table 3. The values of gas phase macroscopic acidity expressed as Gibbs free energy (in $\mathrm{kcal} / \mathrm{mol}$ ) of deprotonation $\left(\Delta \mathrm{G}^{\text {depr }}\right)$ process of canonical model nucleosides and their free radical analogues

\begin{tabular}{|c|c|c|c|c|c|c|c|}
\hline & $\Delta G^{\text {depr }}$ & & $\Delta \mathrm{G}^{\mathrm{depr}}$ & & $\Delta G^{\text {depr }}$ & & $\Delta \mathrm{G}^{\mathrm{depr}}$ \\
\hline $\mathbf{A}$ & 346.7 & C & 339.4 & $T$ & 337.1 & $\mathbf{U}$ & 336.5 \\
\hline $\mathbf{A A}$ & 330.1 & CA & 331.4 & TA & 330.3 & UA & 324.0 \\
\hline $\mathbf{A B}$ & 326.1 & CB & 329.7 & TB & 328.6 & UB & 330.8 \\
\hline $\mathbf{A C}$ & 333.8 & $\mathrm{CC}$ & 332.0 & TC & 331.2 & $\mathbf{U C}$ & 329.9 \\
\hline G & 329.4 & CD & 337.5 & TD & 339.2 & UD & 330.9 \\
\hline GA & 322.2 & CE & 333.6 & TE & 337.1 & $\mathbf{U E}$ & 328.2 \\
\hline GB & 318.1 & & & TF & 326.2 & & \\
\hline GC & 323.7 & & & & & & \\
\hline
\end{tabular}

acidic canonical adenosine. Tautomeric properties of anionic forms are much simpler than for neutral or cationic ones. Usually there is only one isomer that dominates in the gas phase. In the case of AA the most stable anionic form in the vapor state corresponds to deprotonation of amine group, while 8-oxoadenosine and fapy adenosine grant their acidic property from hydrogen atom bound to $\mathrm{N}_{7}$ centre. According to data presented in Table 3 as well as previous report [26] anionic 8-oxoguanosine exists in the gas phase almost exclusively as $\mathrm{N}_{1}$ deprotonated form supplemented with small amount of isomer resulting from deprotonation of exocyclic amine group. For model xanthosine $\mathrm{N}_{3}$ centre is the most acidic. The most probable dissociation centre of model fapy guanosine is $\mathrm{N}_{1}$ atom. In the case of all pyrimidine analogues acidity is granted from amine group. Finally, due to the structure of thymidine and uridine analogues all anionic forms are more likely to be produced as a result of dissociation of proton from $\mathrm{N}_{3}$ centre. This is consistently predicted by both G3 and B3LYP methods in the gas phase. Usually deprotonation does not affect stereochemical properties. In the case of pyrimidine analogues possessing hydroxyl group at $\mathrm{C}_{5}$ centre, the presence of imine group force rotation of $\mathrm{OH}$ site toward $\mathrm{N}_{4}$ nitrogen atom. Almost all of hydroxyl radical modified nucleosides are more acidic in the gas phase if compared to their canonical protoplasts. The only exception is 5,6-dihydrothymine (TD), which is about $2.1 \mathrm{kcal} / \mathrm{mol}$ more acidic then thymidine and 6-hydroxy5,6-dihydrothymine (TE). This derivative is as acidic as thymidine. The highest gain in acidic properties is accom- plished by oxidation of adenosine. This is especially visible for 8-oxoadenosine (AB), for which the Gibbs free energy of deprotonation reaction in the gas phase is about $21.4 \mathrm{kcal} / \mathrm{mol}$, however, than for model non-modified adenosine. Taking into account the total value of the acidity highest susceptibility to deprotonation occurs in case of xanthosine. Thus, although micro-acidities of hydroxyl radical analogues are equivalent to canonical nucleosides the macro-acidity expressed by values of Gibbs free energy of deprotonation process are significantly affected by oxidation .

\section{PROTOLYTIC PROPERTIES IN WATER SOLUTION}

Solvent can profoundly affect the tautomeric properties of heterocyclic compounds. This also includes tautomerism of protonated forms. Although most of hydroxyl radical modified nucleosides are poorly soluble in water, the exact knowledge of the protonation state in this environment is a key factor shaping their biological function. The $\mathrm{pK}_{\mathrm{a}}$ values are directly related to the standard free energy of deprotonation in solution [84-85] and this thermodynamic quantity can be written as the sum of the gas phase and solvation standard Gibbs free energies. Besides, the estimation of the absolute $\mathrm{pK}_{\mathrm{a}}$ values requires the knowledge of the free energy of proton solvation. The exact value is unknown therefore it was determined theoretically [86]. In this paper, value $-265.9 \mathrm{kcal} / \mathrm{mol}$ [86] is assumed as standard Gibbs free energy of proton formation in water. Besides, the majority of molecules may exist in different conformations including rotatable bonds, chirality centres, tautomeric isomers, etc. The determination of $\mathrm{pK}_{\mathrm{a}}$ values, as any thermodynamic quantity, requires taking into account all accessible minima since experimental values represent a weighed average of various isomeric states [26, 27]. Single point calculations providing solvation Gibbs free energies were applied for all hydroxyl radical analogues of model nucleosides and linear regression correction was imposed on resulting $\mathrm{pK}$ values. Table 4 collects all estimated values of $\mathrm{pK}$ for analysed class of compounds. Significant alterations of acidic and basic character imposed by oxidation of model nucleosides are observed. For example, in water environment protonated 2-hydroxyadenosine exists as a mixture of keto-amino and enol-amino tautomer. In either case the $\mathrm{N}_{3}$ centre is the most basic one. However, the basicity of adenosine comes from $\mathrm{N}_{1}$ centre. The alteration of micro-basicity cause one unit downshift of $\mathrm{pK}_{\mathrm{b}}$ values is observed if compared to 
model adenosine. Hence, 2-hydroxyadenosine is less basic than canonical protoplast. Acidic properties of adenosine are granted from hydrogen atoms of amino group. Under basic conditions acidity of AA is manifested via dissociation of hydrogen from $\mathrm{N}_{1}$ atom of keto-amino form. This in turn down shifts significantly the resulting $\mathrm{pK}_{\mathrm{a}}$ value with respect of non-modified adenosine. Similarly to canonical adenosine, the $\mathrm{N}_{1}$ centre is the most basic one for 8-oxoadenosine. Interestingly, the most stable form of neutral $\mathrm{AB}$ is keto-amino tautomer, but after protonation the enol isomer is the most favoured in water. This, however, only slightly alters the $\mathrm{pK}_{\mathrm{b}}$ value and one can treated $\mathrm{AB}$ as basic as adenosine in water solution. Presence of hydrogen atom at $\mathrm{N}_{7}$ centre increases by six units of $\mathrm{pK}_{\mathrm{a}}$ acidic properties of $\mathrm{AB}$ with respect of standard adenosine since in water solution the whole population of anionic form of 8-oxoadenosine consists of $\mathrm{N}_{7}$ deprotonated isomer. Under water conditions fapy adenosine is protonated at $\mathrm{N}_{3}$ centre. This leads to uplifting of the $\mathrm{pK}_{\mathrm{b}}$ value by one unit if compared to canonical adenosine. The acidic properties of $\mathrm{AC}$ coming from deprotonation of $\mathrm{N}_{7}$ atom are significantly higher in comparison with model adenosine since the corresponding $\mathrm{pK}_{\mathrm{a}}$ value increased by about 2.4 unit. Thus, among three analysed here adenosine analogues $\mathrm{AC}$ is the most basic one and $\mathrm{AB}$ has the highest acidity. The following sequence of basicity in water solution can be concluded: $\mathrm{AC}>\mathrm{AB} \approx \mathrm{A}>\mathrm{AA}$. It is worth mentioning that this is not the same order as previously described for gas phase. On the other hand the order of acidity adenosine analogues is the following: $\mathrm{AB}>\mathrm{AA}>\mathrm{AC}>\mathrm{A}$.

In water solution acidity of guanosine originates from deprotonation of exocyclic amino group and basicity is granted from protonation of $\mathrm{N}_{7}$ centre. Protonation of model 8-oxoguanosine in water takes place mainly at $\mathrm{N}_{3}$ centre. Affinity to proton is much lower in this case with respect of standard guanosine and resulting $\mathrm{pK}_{\mathrm{b}}$ values is negative. In fact, this is the only purine among all analysed here with such low basicity. On the other hand, the most acidic centre of GA in water is $\mathrm{N}_{1}$ nitrogen atom. Interestingly, despite exchange of micro-acidity this derivative is characterised by almost the same acidity as canonical guanosine. Model xanthosine similarly to non-modified guanosine is supposed to be protonated at $\mathrm{N}_{7}$ atom in acidic solution and $\mathrm{pK}_{\mathrm{b}}$ value has been down shifted by two $\mathrm{pK}$ units. Although the most stable anionic form of $\mathrm{AB}$ in water is deprotonated at $\mathrm{N}_{1}$ centre acidity of this derivative is almost the same as for canonical guanosine. The last purine analogue analysed here is fapy guanosine. In water protonation takes place exclusively at $\mathrm{N}_{3}$ centre and $\mathrm{N}_{1}$ atom undergoes deprotonation. Only alteration of basicity is observed with respect of canonical guanosine. Thus, all guanosine analogues are weaker bases in water compared with standard guanosine and the following sequence describes decreasing succession of $\mathrm{pK}_{\mathrm{b}}$ values: $\mathrm{G}>\mathrm{GC}>$ GB $>>$ GA. To the contrary, the acidic character of majority of guanosine analogues are unchanged except for GB which is the strongest acid among all analysed here purines.

Table 4. The pK values corresponding to water solution of hydroxyl radical modified model nucleosides. The estimated values of basicities $\left(\mathrm{pK}_{\mathrm{b}} ; \mathrm{B}+\mathrm{H}^{+}=\mathrm{BH}^{+}\right)$and acidities $\left(\mathrm{pK}_{\mathrm{a}} ; \mathrm{AH}=\mathrm{A}^{-}+\mathrm{H}^{+}\right)$correspond to values of solvation Gibbs free energies estimated based on gas phase geometries

\begin{tabular}{|c|c|c|c|c|c|}
\hline & $\mathrm{pK}_{\mathrm{b}}$ & $\mathrm{pK}_{\mathrm{a}}$ & & $\mathrm{pK}_{\mathrm{b}}$ & $\mathrm{pK}_{\mathrm{a}}$ \\
\hline $\mathbf{A A}$ & 2.7 & 10.8 & TA & -6.2 & 10.5 \\
\hline $\mathbf{A B}$ & 4.1 & 9.3 & TB & -7.1 & 9.2 \\
\hline $\mathbf{A C}$ & 4.9 & 12.1 & TC & -5.7 & 9.9 \\
\hline A & 3.8 & 15.5 & TD & -5.1 & 11.6 \\
\hline GA & -0.6 & 9.5 & TE & -6.0 & 10.7 \\
\hline GB & 1.4 & 6.0 & TF & -3.2 & 8.6 \\
\hline GC & 1.8 & 9.6 & $\mathbf{T}$ & -4.8 & 10.4 \\
\hline $\mathbf{G}$ & 3.4 & 9.8 & UA & -7.3 & 7.7 \\
\hline $\mathbf{C A}$ & 1.9 & 14.8 & UB & -4.1 & 9.6 \\
\hline CB & 3.8 & 11.4 & UC & -5.7 & 9.2 \\
\hline $\mathrm{CC}$ & 4.4 & 13.5 & UD & -5.4 & 9.9 \\
\hline CD & 4.5 & 13.6 & UE & -7.0 & 9.3 \\
\hline $\mathbf{C E}$ & 4.3 & 12.0 & $\mathbf{U}$ & -4.3 & 10.1 \\
\hline C & 4.2 & 14.7 & & & \\
\hline
\end{tabular}

For all cytidine analogues in keto-amino tautomeric from the $\mathrm{N}_{3}$ atom is the most probable centre of protonation in water solution. Resulting $\mathrm{pK}$ 's values are collected in Table 4. Although basic character of standard cytidine is also granted from this site the value of $\mathrm{pK}_{\mathrm{b}}$ for CA is about two units lower with respect of non-modified cytidine. Thus, significant decrease of basicity is observed in this case. It is worth mentioning that in the gas phase the basicity of $\mathrm{CA}$ and $\mathrm{C}$ are roughly the same. The rest of cytidine analogues are almost as basic as $\mathrm{C}$ in water and corresponding $\mathrm{pK}_{\mathrm{b}}$ values are within 0.5 unit. Thus, the order of basicity in water can be describes as follows: $\mathrm{CD} \approx \mathrm{CC} \approx \mathrm{CE} \approx \mathrm{C} \approx \mathrm{CB}<<\mathrm{CA}$. Cytidine and its free radical analogues are very weak acids and under extremely basic conditions all can dissociate proton from amino group of keto-amino tautomers. However, most cytidines are stronger acids than non-modified cytosine. The only excep- 
tion is 5-hydroxycytydine, which acidity is almost identical with canonical pyrimidine. The most acidic is cytidine glycol with $\mathrm{pK}_{\mathrm{a}}$ lowered by more then three units with respect of cytosine. Thus, the following sequence characterises acidites of cytidine analogues, $\mathrm{CB}>\mathrm{CE} \mathrm{CC}>\mathrm{CD}$ $>\mathrm{C} \approx \mathrm{CA}$.

Basic character of thymidine, uridine and their free radical analogues is strictly theoretical. As it was documented in Table 4, all are characterised by negative values of $\mathrm{pK}_{\mathrm{b}}$. This is quite understandable since only oxygen atoms may undergo protonation. The proton affinity of exocyclic groups is much lower compared to hydrogen-free atoms constituting the heterocyclic ring. However, all these pyrimidines posses very acidic $\mathrm{N}_{3}$ centre. Thus, all thymidine and uridine analogues are much more acidic than the rest of compounds studied here. The follwoing succesion of acidities of thymidine analogues may be concluded: $\mathrm{TF}>\mathrm{TB}>\mathrm{TC}>\mathrm{T} \approx \mathrm{TA} \approx \mathrm{TE}>\mathrm{TD}$. In case of uridine derivatives all hydroxyl radical analogues are more acidic than uridine and the following sequence may be proposed: $\mathrm{UA}>\mathrm{UC}>\mathrm{UE}>\mathrm{UB}>\mathrm{UD} \approx \mathrm{U}$.

Above presented data univocally demonstrated that the oxidation of nucleosides leads not only to alteration of $\mathrm{pK}$ values with respect of canonical species changing acidity and basicity but also can imposes modification in the micro-protolytic properties.

\section{Oxidative susceptibility}

The process of carcinogenesis is known as a multistage phenomena [88-90]. In the first phase conversion of the pre-carcinogens into electrophilic reagents takes place [91, 92]. Modification of the DNA imposed by such reacting agents occurs as a result of electron donation from $\mathrm{HOMO}$ located on DNA site to LUMO of carcinogen. It is then LUMO energy which is the primary source of information of the carcinogenic role of any agent and high energies of HOMO identify the probable target for carcinogen attack. It is well known that guanine has the lowest reduction potential among the four nucleobases [1, 2] and consequently it is preferentially oxidized to its radical cation and further to stable oxidized forms as for example 8-oxoguanine. This also explains why guanine is the most probable site for holes trapping [93-95]. Besides, series guanine sequences stacked within one B-DNA strand have even lower ionization potentials than single guanine [96]. Such sequences are more probable sites for oxidation. This is of particular importance since several hot spot codons of tumor suppressor genes as well as human ras-protooncogenes are rich in GG sequences [97]. Also GGG triads are common in telomeric fragments of cellular DNA [98]. There are experimental evidences that 8-oxoguanine can be even better substrate for oxidation than any of the natural nucleosides [99-101]. It is interesting to see if other hydroxyl radical derived analogues can also play such a role. For this purpose the values of ionization potential (IP) should be estimated for each of purine and pyrimidine analogue. The simplest way of IP estimation relies on the Koopmans theorem. It simply assumes that IP $\approx-$ HOMO. Additionally vertical IP can be calculated as the energy or Gibbs free energy difference between cationic and neutral forms without relaxation of the geometry. Adiabatic IP includes the geometry relaxation after ionization process. All three measure were successfully used for description of susceptibility to chemical carcinogens of hydroxyl radical modified model nucleosides [67].

Application of AM1-CI semiempirical quantum chemistry method to canonical nucleobases [65] seems to be reasonable and inexpensive choice since it can duplicate available experimental data [102] of ionization potentials of canonical DNA bases. The application of this methodology [65] to all stable tautomers of hydroxyl radical analogues leads to values presented in Table 5. Most of analysed species are characterised by higher values of IP than model guanosine. However, there are several interesting exceptions.

Table 5. The values of adiabatic and vertical ionization potentials (in $\mathrm{eV}$ ) of four DNA bases and their hydroxyl radical analogs estimated based on AM1-CI semiempirical quantum chemistry method

\begin{tabular}{|c|c|c|c|c|c|}
\hline & IP $^{\text {adiab }}$ & $\mathrm{IP}^{\mathrm{vert}}$ & & IP $^{\text {adiab }}$ & $\mathrm{IP}^{\mathrm{ver}}$ \\
\hline A & 7.95 & 8.22 & $\mathbf{T}$ & 8.47 & 8.85 \\
\hline AA1 & 7.85 & 8.16 & TA & 8.70 & 9.11 \\
\hline AA2 & 7.57 & 7.82 & TB & 9.02 & 9.77 \\
\hline $\mathbf{A B}$ & 7.94 & 8.50 & TC & 8.96 & 9.55 \\
\hline $\mathbf{A C}$ & 7.87 & 8.53 & TD & 8.98 & 9.48 \\
\hline G & 7.57 & 8.04 & TE & 9.37 & 9.90 \\
\hline GA1 & 7.34 & 7.92 & TF & 9.06 & 9.41 \\
\hline GA2 & 7.60 & 8.13 & $\mathbf{U}$ & 8.79 & 9.17 \\
\hline GB & 8.17 & 8.51 & UA & 10.01 & 10.42 \\
\hline GC1 & 7.02 & 7.66 & UB & 8.08 & 8.56 \\
\hline GC2 & 7.42 & 8.13 & $\mathbf{U C}$ & 8.22 & 8.66 \\
\hline C & 8.36 & 8.64 & UD & 9.08 & 9.53 \\
\hline CA & 7.80 & 8.28 & UE & 9.41 & 9.84 \\
\hline CB & 8.80 & 9.36 & & & \\
\hline $\mathrm{CC}$ & 7.75 & 8.30 & & & \\
\hline CD & 8.67 & 9.24 & & & \\
\hline CE & 8.46 & 8.98 & & & \\
\hline
\end{tabular}


The following analogues are supposed to posses higher susceptibility to chemical carcinogens than guanine: 6,8-diketo (GA1) tautomer of 8-oxoguanosine, 6-enol (GC1) and 6-keto (GC2) tautomers of fapy-guanosine and 2-keto tautomer of 2-oxoadenosine (AA2) [65]. Thus, such centres if present in DNA double helix are expected to be prone to further oxidation and can form hot spots for carcinogen attacks.

\section{N-GLYCOSID BOND STABILITIES}

The linkage that connects sugar-phosphate backbone with nucleoside in the polynucleotide chains is termed $\mathrm{N}$-glycosidic bond. Breaking of this bond is one of fundamental mechanisms by which modified nucleobases are removed from cellular DNA chains. The presence of apurine or apyrimidine sites is one of the common intermediates in the repair of many damages to DNA. Although in cellular condition the hydrolysis of N-glycosidic bond involves activity of specific glycosylases [103, 104] it is interesting to know the strength of N-glycosidic bond of free radical derived analogues. This is also the first step in understanding of the mechanism of non-enzymatic nucleosides hydrolysis. It is assumed that nucleosides, nucleotides and their analogues hydrolyze through fast initial protonation followed by the hydrolysis rate-limiting process of the $\mathrm{N}$-glycosidic bond cleavage $[105,106]$. The reaction mechanism is $\mathrm{pH}$ related since protonation is the first step of $\mathrm{N}$-glycosidic bond hydrolysis. In the second stage actual dissociation of sugar moiety takes place and nucleobase is released. Finally in the third step eventual re-tautomerisation takes place and most stable form is adopted by nucleobase $[60,61]$. Thus, stability of the N-glycosidic bond can then be characterised by values of Gibbs free energies of the second step $\left(\Delta \mathrm{G}_{\mathrm{N} \text {-glyc }}\right)$. The general thermodynamic trend of depurination or depyrimidation can be expressed as the sum of the first two steps $\left(\Delta \mathrm{G}_{\mathrm{dep}}\right)$. The population of protonated and neutral tautomers must obviously be taken into account. The values of Gibbs free energies corresponding to gas phase and water solution were taken from calculations presented in the previous sections on $\mathrm{B} 3 \mathrm{LYP} / \mathrm{aDZ}$ level and resulting values are collected in Table 6. Since presented values are related to Gibbs free energies characterising canonical nucleosides the negative values typify weaker stabilities in comparison to onmodified nucleosides. As it can be seen, the majority of derivatives are characterised by weaker N-glycosidic bonds in both the gas phase and water solution. Among adenosine analogues only $\mathrm{AB}$ seems to be more susceptible to $\mathrm{N}$ glycosidic bond hydrolysis than canonical adenosine in the gas phase. In water solution situation change significantly and $\mathrm{AA}$ becomes more prone to $\mathrm{N}_{9}-\mathrm{C}_{1}^{\prime}$ breaking. Both effects are slightly less than $2 \mathrm{kcal} / \mathrm{mol}$. The overall trend of depurination is higher for all adenosine derivatives in comparison to standard adenosine except for AA in the water solution. This suggests that although depurination is more energetically favoured for AA, the Gibbs free energies of both protonation and $\mathrm{N}$-glycosidic bond hydrolysis are less preferred with respect of adenosine. Thermodynamic measure of N-glycosidic bond strength presented in Table 6 suggests that all guanosine analogues are to be considered as more prone to hydrolysis compared to standard guanosine. This effect remains also in water condition, although is significantly reduced by polar environment.

Table 6. Quantitative description of relative N-glycosidic bond stabilities of hydroxyl radical modified DNA bases. Relative values of Gibbs free energies of $\mathrm{N}$-glycosidic bond dissociation $\left(\Delta \Delta \mathrm{G}_{\mathrm{N}-\mathrm{glyc}}\right)$ and the overall thermodynamic trend of hydrolysis $\left(\Delta \Delta \mathrm{G}_{\mathrm{dep}}\right)$ are described with respect of canonical nucleosides

\begin{tabular}{|c|c|c|c|c|}
\hline & \multicolumn{2}{|c|}{$\begin{array}{c}\Delta \Delta \mathrm{G}_{\mathrm{N}-\mathrm{glyc}} \\
{[\mathrm{kcal} / \mathrm{mol}]}\end{array}$} & \multicolumn{2}{|c|}{$\begin{array}{c}\Delta \Delta \mathrm{G}_{\mathrm{dep}} \\
{[\mathrm{kcal} / \mathrm{mol}]}\end{array}$} \\
\hline & gas & water & gas & water \\
\hline $\mathbf{A A}$ & 2.74 & -1.93 & -0.15 & 1.05 \\
\hline $\mathbf{A B}$ & -1.83 & 0.62 & -0.10 & -0.45 \\
\hline $\mathbf{A C}$ & 2.33 & 3.24 & -2.09 & -0.73 \\
\hline GA & -9.73 & -5.42 & 1.34 & 0.61 \\
\hline GB & -16.84 & -4.17 & -7.55 & -3.50 \\
\hline GC & -4.99 & -6.53 & -2.26 & -3.32 \\
\hline CA & 0.37 & 0.74 & -0.15 & 1.45 \\
\hline CB & -2.93 & -0.76 & 0.14 & -0.09 \\
\hline $\mathrm{CC}$ & -3.52 & -2.56 & -6.59 & -3.09 \\
\hline CD & -0.88 & 1.45 & 2.11 & 0.09 \\
\hline CE & -3.93 & 0.33 & 0.50 & 1.10 \\
\hline $\mathbf{T A}$ & -1.69 & 3.73 & 0.15 & -0.15 \\
\hline TB & -2.16 & -2.20 & 2.87 & 0.46 \\
\hline TC & -1.42 & -0.54 & 0.31 & 0.61 \\
\hline TD & -1.02 & 1.11 & 0.56 & 1.17 \\
\hline TE & -2.80 & -1.73 & 1.88 & 0.26 \\
\hline TF & -0.40 & 4.07 & 0.15 & -0.40 \\
\hline UA & -9.80 & -11.15 & 0.39 & -1.90 \\
\hline UB & -4.13 & -2.66 & -1.97 & -1.62 \\
\hline $\mathbf{U C}$ & -4.22 & -5.77 & -0.06 & -0.08 \\
\hline UD & -2.49 & -3.51 & 0.26 & 1.27 \\
\hline $\mathbf{U E}$ & -4.78 & -5.31 & -0.23 & -0.30 \\
\hline
\end{tabular}


For majority of pyrimidine analogues $\Delta \Delta \mathrm{G}_{\mathrm{N}-\mathrm{glyc}}$ are also negative both in gas phase and water solutions. There are only few exception, namely CA, CD, TA, TD, TF in water and additionally $\mathrm{CA}$ in the gas phase. The general trend of depyrimidisation is usually small except of $\mathrm{CC}$ for which is the smallest among all analysed pyrimidine analogues.

Hence, for most of species the oxidation of purines and pyrimidine model nucleosides increase liability of N-glycosidic bond but there are few exceptions, which could not be foreseen before actual Gibbs free energies calculations. The most significant increase of $\mathrm{N}$-glycosidic bond strength in comparison to canonical nucleosides is observed for $\mathrm{TF}$, $\mathrm{TA}$ and $\mathrm{AC}$

\section{CODING ABILITIES OF HYDROXYL RADICAL MODIFIED NUCLEOBASES}

The abilities of intermolecular hydrogen bond formation is directly related to tautomeric form adopted by any hydroxyl radical analogue. Migration of proton between electronegative centres exchange positions of donor $\{+\}$ and acceptor $\{-\}$ sites. In amino- and enol- groups protons are supposed to play donor role. On the contrary, iminoand keto- sides are considered as acceptors. Also nitrogen atoms placed within pyrimidine or imidazole rings can also be potentially involved in hydrogen bond formation. For example $\mathrm{N}_{1}$ atom of purines and $\mathrm{N}_{3}$ of pyrimidines play important role in Watson-Crick boding. On the other hand, Hoogsteen-type of hydrogen bonded complexes uses $\mathrm{N}_{7}$ atom of purines. Hydrogen bonding pattern of A-T pairs can be symbolized as $\{+-\}$ and $\{-+\}$ for canonical adenine and thymine, respectively. Analogically G-C pair involving three hydrogen bonds can be described as $\{-++\}$ and $\{+--$ \} for native guanine and cytosine, respectively. In such notation direction from major groove to minor one is used. In this sense alteration of tautomeric form can potentially lead to exchanging of hydrogen bonding pattern, which in the first simplification determine coding abilities of hydroxyl radical modified DNA bases. In Table 7 there are collected coding patterns for most stable tautomeric forms of all analysed derivatives. Such characteristics are only the first qualitative step and should be extended by detailed quantification of affinities of hydrogen bonded pairs including B-DNA environment. This important aspect is still unknown and deserve further attention although some initial studies were already published [69].

The mispairing potential of modified adenine was studied [54] for two most stable tautomers, namely AA1 and AA2. Although both species are characterized by different bonding patterns, as it is indicated in Table 7, they can form stable hydrogen bonded complexes with all four standard DNA bases [54]. The most stable pairs involving enol tautomer (AA1) are those with guanine and cytosine [109]. Interestingly the stabilization energy of these pairs is higher than for standard $\mathrm{A}-\mathrm{T}$ pair in the gas phase. Also pairs produced by keto tautomer (AA2) with guanine and thymine are characterised by stronger interactions compared to A-T pair. However, in the presence of the water solvent, the relative stabilities of all studied pairs are significantly reduced. Despite of this fact, pairs formed by AA1 with guanine and AA2 with thymine are more stable than hydrated adenine-thymine pair [109]. The mispairing character of $\mathrm{AB}$ is much less pronounced than for 2-hydroxyadenine. Although in the gas phase $\mathrm{AB}$ is able to form pairs with thymine, guanine and cytosine that are more stable than A-T pair, but in polar environment only pairs with thymine remain energetically more favourable than standard A-T pair [109]. Nevertheless, miscoding with guanine is possible although with much lesser extend than for 2-hydroxyadenine. Fapy adenine is known as a lesion that strongly blocks replication processes [1-3]. Our investigation [57] suggests that $\mathrm{AC}$ is able to form stable pairs with all four standard nucleobases in the gas phase. All these complexes except those involving adenine are characterised by higher stabilisation energy than standard A-T pair. In the polar environment the relative stabilisation energies of all complexes of fapy adenine with all four DNA bases are almost identical.

Coding potential of 8-oxoguanine [50] was described both in the gas phase as well as in polar environment. The 6,8-diketo isomer of GA has two donor sites located on the $\mathrm{N}_{1}$ and $\mathrm{N}_{2}$ atoms. Besides, one acceptor site is placed at $\mathrm{O}_{6}$ centre. Hence, the ability for $\mathrm{H}$-bond formation is potentially the same as for standard guanine $\{-++\}$. Consequently, formation of complex stabilized by three hydrogen bonds is possible in either case between $\mathrm{G}-\mathrm{C}$ and GA-C. On the contrary the 6-enol-8-keto tautomer of GA has two donor sites located on the $\mathrm{N}_{2}$ and $\mathrm{O}_{6}$ atoms and $\mathrm{N}_{1}$ centre stands for acceptor site. Thus, the coding abilities denoted as $\{+-+\}$ are different if compared with standard guanine and can lead to mispairing. In apolar conditions, the most stable pairs of 6,8-diketo tautomer (GA1) comprise cytosine or guanine. For both complexes the stabilisation energies exceed energy of formation of canonical G-C pair. The 6-enol-8-keto tautomer (GA2) can also be involved in a variety of dimers, but pairs with thymine and adenine are more favoured than standard G-C ones. Moreover, less favoured tautomers such as 6-enol-2-imino or 6,8-dienol-2-imino, are also potentially able to pair with cytosine and guanine. Despite lower stability of these 
tautomers, the resulting pairs are characterised by higher stabilisation energy than the standard G-C pair. Good pairing of guanine analogue with cytosine is not surprising, due to great geometric and electrostatic similarities between the 6,8-diketo form of 8-oxoguanine and standard guanine. However, very stable complexes with guanine and thymine, if they occur in the DNA interior, may be responsible for the GC-CG transversion and GC-AT transition. The strong hydrogen bonds may stabilise pairs with canonical DNA bases, not only for the most stable tautomer but also for other less probable ones. Since the tautomeric form determines the coding ability of 8-oxoguanine, the shift in the tautomeric equilibrium may exchange the mispairing character of this guanine derivative. This might be the reason for the complete lack of specific 8-oxoguanine pairing in some B-DNA sequences [108]. The pairing properties of fapy guanine [57] are complex and strongly depend on the tautomeric form. In the gas phase the amino-enol tautomer (GC2) is able to form stable pars with thymine and cytosine, while the amino-keto isomer (GC1) forms the most stable complexes with cytosine and guanine. The presence of polar environment does not significantly alter the pairing abilities of fapy guanine. However, its pairs with thymine are at least as stable as Watson-Crick GC pair. Thus, one can expect that mispairing abilities of fapy guanine can potentially leads to $\mathrm{GC} \rightarrow \mathrm{AT}$ transitions.
The coding potential of most of pyrimidine analogues is similar to non-modified pyrimidine. This can be clearly visible after inspection of the hydrogen bonding patterns presented in Table 7. Hence, stable pairs comprising cytosine analogues are formed with guanine. Adenine is involved in formation of stable complexes with thymine and uracil derivatives. However, some species may also be involved in formation of stable non-standard pairs with all four canonical nucleobases $[50,52,56]$. For example both keto-amino and keto-imino tautomers of 5-hydroxycytosine [52] are able to form stable pairs with guanine, cytosine and to a lesser extent with thymine. The first type of interactions does not lead to miscoding abilities but formation of all other complexes may be responsible for observed miscoding properties. In polar conditions there is still high potential for hydrogen bonding with guanine and cytosine. The rest of analyzed here cytosine analogues is able to form stable pairs both with guanine and cytosine. In non-polar conditions the 5,6-dihydroxycytosine pairs with cytosine in addition to a normal pairing with guanine. This may be the reason of potential $\mathrm{C} \rightarrow \mathrm{G}$ transversions. The polarity of the environment may have significant impact on the pairs stabilization energies. However, for all cytosine analogues complexes, the pairs formed with cytosine and guanine are more stable then canonical G-C pair.

Thymine analogues can form stable pairs mostly with adenine, what does not introduce any miscoding abilities

Table 7. The pairing capabilities of hydroxyl radical modified nucleobases. Only those pairs are included, which are characterized by higher stabilization energies than standard pairs. The notation of coding patterns of canonical bases is the following: $\mathrm{A}\{+-\}, \mathrm{G}\{-++\}, \mathrm{C}\{+--\}, \mathrm{T}\{-+-\}$ and $\mathrm{U}\{-+-\}$

\begin{tabular}{|c|c|c|c|c|c|c|c|}
\hline \multicolumn{4}{|c|}{ Pairs more stable than canonical A-T } & \multicolumn{4}{|c|}{ Pairs more stable than canonical G-C } \\
\hline derivative & pattern & gas phase & polar conditions & derivative & pattern & gas phase & polar conditions \\
\hline AA1 & $\{+-+\}$ & $\mathrm{G}>\mathrm{C}$ & G & GA1 & $\{-++\}$ & $\mathrm{G} \approx \mathrm{C}$ & $\mathrm{G} \approx \mathrm{C}>\mathrm{T}$ \\
\hline AA2 & $\{++-\}$ & $\mathrm{G}>\mathrm{T}$ & $\mathrm{T}$ & GA2 & $\{+-+\}$ & - & $\mathrm{T}$ \\
\hline $\mathbf{A B}$ & $\{+-\}$ & $\mathrm{G} \approx \mathrm{C}>\mathrm{T}$ & $\mathrm{T}$ & GC1 & $\{-++\}$ & $\mathrm{C}>\mathrm{G}>\mathrm{T}$ & $\mathrm{C}>\mathrm{G} \approx \mathrm{T}$ \\
\hline $\mathbf{A C}$ & $\{+-\}$ & $\mathrm{G}>\mathrm{C}>\mathrm{T}$ & $\mathrm{T}$ & GC2 & $\{+-+\}$ & $\mathrm{G}>\mathrm{T}>\mathrm{A}$ & $\mathrm{T}>\mathrm{A}$ \\
\hline TA & $\{-+-\}$ & $\mathrm{G}>\mathrm{A}$ & $\mathrm{G} \approx \mathrm{A}$ & CA3 & $\{+--\}$ & $\mathrm{G}>\mathrm{C}>>\mathrm{T}$ & $\mathrm{G}>\mathrm{C}$ \\
\hline TB & $\{-+-\}$ & $\mathrm{G}>\mathrm{C}>\mathrm{A}$ & - & CB2 & $\{+--\}$ & G & $\mathrm{G}>\mathrm{C} \approx \mathrm{A} \approx \mathrm{T}$ \\
\hline TC & $\{-+-\}$ & $\mathrm{G}>\mathrm{C}>\mathrm{A}$ & - & $\mathrm{CC2}$ & $\{+--\}$ & $\mathrm{G}>\mathrm{C}$ & $\mathrm{C}>\mathrm{G}$ \\
\hline TD & $\{-+-\}$ & $\mathrm{G} \gg \mathrm{C}>\mathrm{A} \approx \mathrm{T}$ & G & CD1 & $\{+--\}$ & $\mathrm{G} \gg \mathrm{C}$ & $\mathrm{G}>\mathrm{C}$ \\
\hline TE & $\{-+-\}$ & $\mathrm{G} \gg \mathrm{C} \approx \mathrm{A}$ & G & $\mathbf{C E}$ & $\{+--\}$ & $\mathrm{G} \gg \mathrm{C}$ & $\mathrm{G} \approx \mathrm{C}$ \\
\hline TF & $\{-+-\}$ & $\mathrm{G}>\mathrm{A}>\mathrm{C}$ & A & & & & \\
\hline $\mathbf{U A}$ & $\{-+-\}$ & $\mathrm{G} \gg \mathrm{C} \approx \mathrm{A}$ & $\mathrm{G} \approx \mathrm{A}$ & & & & \\
\hline UB & $\{-+-\}$ & $\mathrm{G}>\mathrm{A}>\mathrm{C}$ & $\mathrm{A}>\mathrm{G}$ & & & & \\
\hline $\mathbf{U C}$ & $\{-+-\}$ & $\mathrm{G}>\mathrm{A}>\mathrm{C}$ & A & & & & \\
\hline UD & $\{-+-\}$ & $\mathrm{G}>\mathrm{C} \approx \mathrm{A} \approx \mathrm{T}$ & G & & & & \\
\hline UE & $\{-+-\}$ & $\mathrm{G}>\mathrm{C}>\mathrm{A}$ & $\mathrm{G} \approx \mathrm{A}$ & & & & \\
\hline
\end{tabular}


by these derivatives [50]. Apart from this, some analogues can have potential miscoding character, which strongly depends on the polarity of the environment. For example in non-polar conditions the 5-hydroxymethyluracil is able to form pairs with guanine and adenine that are strongly attracted than adenine and thymine in its canonical complex. The thymine glycol can pair with guanine, cytosine and adenine. The most stable pairs of 5-formyldeoxyuracil are formed with guanine and adenine. Such derivatives as 5,6-dihydrothymine and 6hydroxy-5,6-dihydrothymine apart from adenine can pair with guanine and cytosine. Polar conditions significantly affect the pairs stabilisation. Usually a reduction in the pairs relative stability is observed and for most dimers stabilisation energy becomes less than corresponding value for the adenine-thymine pair. However, the mispairing potential is still significant, especially for TA, TD and TE. In all cases complexes are potentially formed with guanine. Thus, modification of thymine both in aerobic and anaerobic conditions $[52,56]$ can lead to products which are characterised by significant ability to form intermolecular hydrogen bonds with standard DNA bases. Uracil derivatives can form stable pairs not only with adenine but also with all other DNA bases $[52,56]$. There is a problem with interpretation of the relative stabilities of pairs formed by these species since they can be considered as products of deamination of cytosine analogues or as products of degradation of thymine lacking methyl group. Here stabilisation of complexes formed by uracil analogues are related to standard A-T pair. As it is presented in Table 7, in non-polar conditions all uracil derivatives can pair with guanine, cytosine and adenine with varying succession. Under polar conditions adenine and guanine are involved in complexes that are more stable than A-T one. The only exception is observed for 5-hydroxy-5,6-dihydrouracil, which can be involved only in pairing with guanine.

It is also worth mentioning that rare tautomers, despite their lower stabilities, can also potentially be involved in pairing with standard nucleic acid bases since corresponding stabilization energies can exceed the amount related to the most probable isomers. This fact makes the problem of miscoding properties more complex and deserves further interests especially inside B-DNA environment and imposed structural restrictions on mutual conformations of bases involved in pairing.

\section{CONCLUSIONS}

The class of heterocyclic compounds comprising hydroxyl radical modified nucleobases is characterized by great heterogeneities of physicochemical properties. Most of these analogues occur spontaneously at physiological conditions in cellular DNA. Their presence is proved either directly by instrumental measurements of chromatin DNA hydrolysates or indirectly by elevation of enzymatic defence systems. Besides, observed exchanging of genetic code, affection of replication or transcription processes, even blocking these processes confirm crucial role of hydroxyl radical modified DNA bases in vital biochemical activities of living cells. Modified nucleobases or nucleosides can be significantly different in many physicochemical properties from their canonical protoplasts. Among many differences the tautomeric equilibriums of neutral, protonated and deprotonated forms are of primary interest. Tautomeric equilibriums determine not only GPB or pK values but also affects such features as oxidative susceptibility and N-glycosidic bond stabilities. Tautomerism also profoundly affect coding abilities, which are directly responsible for observed cytotoxic properties of many lesions. Still further investigations are indispensable for accurate descriptions of the molecular origin of observed biological consequences of modified DNA bases. For example there are completely not know structural, energetic and dynamic consequences of presence of hydroxyl radical modified DNA bases in double stranded polynucleotide chains. These aspects will be addressed in the forthcoming projects.

\section{Acknowledgement}

Results were obtained the part of computational grant No 39 of Poznań Supercomputing and Networking Center (Poznań, Poland). The allocation of computational facilities are greatly appreciated.

\section{References}

[1] C. von Sonntag, Free-Radical-Induced DNA Damage and Its Repair, A Chemical Perspective. Springer-Verlag, Berlin, Heidelberg, New York 2006.

[2] B. Halliwell, J.M.C. Gutteridge, Free Radicals in Biology and Medicine. Clarendon Press, Oxford 1999.

[3] C. Rice-Evans, B. Halliwell, G.G. Lunt, Free Radicals and Oxidative Stress: Environment, Drugs and Food Additives. Portland Press, London 1995.

[4] M.S. Cooke, M.D. Evans, M. Dizdaroglu, J. Lunec, Oxidative DNA damage: mechanisms, mutation, and disease, FASEB J. 17, 1195-1214 (2003).

[5] M. Genestra, Oxyl radicals, redox-sensitive signaling cascades and antioxidants. Cell. Signal. 19, 1807-1819 (2007).

[6] M. Dizdaroglu, Chemical determination of free radical induced damage to DNA, Free Radic. Biol. Med. 10, 225-242 (1991). 
[7] M. Dizdaroglu, Oxidative damage to DNA in mammalian chromatin. Mutat. Res. 275, 331-342 (1992).

[8] M. Dizdaroglu, Mechanisms of free radical damage to DNA. in: O.I. Aruoma, B. Halliwell (ed) DNA and free radicals: techniques, mechanisms and applications. St. Lucia: OICA International, 1998.

[9] B. Halliwell, O.I. Aruoma, DNA damage by oxygen-derived species: its mechanism, and measurement using chromatographic methods. in Molecular Biology of Free Radical Scavenging Systems (ed. J.G. Scandalios) Cold Spring Harbor Laboratory Press, Cold Spring Harbor, NY 1992.

[10] R. Oliński, D. Gackowski, R. Rozalski, M. Foksinski, K. Bialkowski, Oxidative DNA damage in cancer patients: a cause or a consequence of the disease development? Mutat. Res. 531, 177-190 (2003).

[11] K. Kohda, M. Tada, A. Hakura, H. Kasai, Y. Kawazoe, Formation of 8-hydroxyguanine residues in DNA treated with 4-hydroxyaminoquinoline 1-oxide and its related compounds in the presence of seryl-AMP. Biochem. Biophys. Res. Commun. 149 (3), 1141-1148 (1987).

[12] B. Commoner, J. Townsend, G.E. Pake, Free radicals in biological materials. Nature 174, 689-691 (1954).

[13] S. Fu, R. Dean, M. Southan, R. Truscott, The hydroxyl radical in lens nuclear cataractogenesis. J. Biol. Med. 273, 28603-28609 (1998).

[14] H. Kasai, P.F. Crain, Y. Kuchino, S. Nishimura, A. Ootysuyama, H. Tanooka, Formation of 8-hydroxyguanine moiety in cellular DNA by agents producing oxygen radicals and evidences for its repair. Carcinogen. 7, 1849-1851 (1986).

[15] S. Akasaka, K. Takimoto, K. Yamamoto, G:C-->T:A and $G: C-->C: G$ transversions are the predominant spontaneous mutations in the Escherichia coli supF gene: an improved lacZ(am) E. coli host designed for assaying pZ189 supF mutational specificity. Mol. Gen. Genet. 235, 173-178 (1992).

[16] A.R. Collins, C. Gedik, S. Wood, A. White, J. Dubois, P. Duez, J-F. Rees, R. Legall, L. Degand, S. Loft, A. Jensen, H. Poulsen, A. Weimann, B.R. Jensen, J. Cadet, T. Douki, J-L. Ravanat, H. Faure, M. Tripier, I. Morel, O. Sergent, P. Cillard, B. Morin, B. Epe, N. Phoa, A. Hartwig, A. Pelzer, P. Dolara, C. Casalini, F. Guglielmi, C. Luceri, H. Kasai, R. Kido, R. Olinski, K. Bialkowski, Z, Duračková, L. Hlinčiková, P. Korytar, M, Dušinská, C. Mislanová, J. Viña, A. Lloret, L. Möller, T. Hofer, E. Gremaud, L. Fay, R. Stadler, J. Eakins, F. Pognan, J. O'Brien, R. Elliott, S. Astley, A. Bailley, K. Herbert, D. Chauhan, F. Kelly, C. Dunster, J. Lunec, I. Podmore, P. Patel, S. Johnson, M. Evans, A. White, R. Tyrrell, M. Gordon, C. Wild, L. Hardie, E. Smith, Inter-laboratory Validation of Procedures for Measuring 8-oxo-7,8-dihydroguanine/8-oxo7,8-dihydro-2'-deoxyguanosine in DNA. Free Radic. Res. 36 (3), 239-245 (2002)

[17] S. Shibutani, M. Takeshita, A.P. Grollman, Insertion of specific bases during DNA synthesis past the oxidationdamaged base 8-oxodG. Nature 349, 431-434 (1991).

[18] M. Moriya, C. Ou, V. Bodepudi, F. Johnson, M. Takeshita, A.P. Grollman, Site-specific mutagenesis using a gapped duplex vector: a study of translesion synthesis past 8-oxodeoxyguanosine in E. coli. Mutat. Res. 254, 281-288 (1991).

[19] S.J. Culp, B.P. Cho, F.F. Kadlubar, F.E. Evans, Structural and conformational analyses of 8-hydroxy-2'-deoxyguanosine. Chem. Res. Toxicol. 2, 416-422 (1989).

[20] M. Aida, S. Nishimura, An ab initio molecular orbital study on the characteristics of 8-hydroxyguanine, Mutat. Res. 192, 83-89 (1987).
[21] M. Nonella, G. Hanggi, E. Dubler, The geometry of the neutral, protonated or coordinated purine derivatives hypoxanthine, xanthine, allopurinol and alloxanthine: quantum chemical and X-ray crystallographic studies. J. Mol. Struct. THEOCHEM 279, 173-190 (1993).

[22] D. Venkateswarlu, J. Leszczynski, Tautomeric equilibria in 8-oxopurines: Implication for mutagenecity. J. Comput. Aided Mol. Des. 12, 373-382 (1998).

[23] J. Gu, J. Leszczynski, Influence of the Oxygen at the C8 Position on the Intramolecular Proton Transfer in C8Oxidative Guanine. J. Phys. Chem. A 103, 577-584 (1999).

[24] K. Miaskiewicz, J. Miller and R. Osman, $A b$ initio theoretical study of the structures of thymine glycol and dihydrothymine. Int. J. Radiat. Biol. 63, 677- 686 (1993).

[25] K. Miaskiewicz, J. Miller, R. Ostrein, R. Osman, Molecular dynamics simulations of the effects of ring-saturated thymine lesions on DNA structure. Biopolymers 33, 113-124 (1994).

[26] Y. H. Jang, W.A. Goddard III, K.T. Noyes, L.C. Sowers, S. Hwang, D.S. Chung, First Principles Calculations of the Tautomers and $p K_{a}$ Values of 8-Oxoguanine: Implications for Mutagenicity and Repair. Chem. Res. Toxicol. $15,1023-1035$ (2002).

[27] K.N. Rogstad, Y.H. Jang, L.C. Sowers. W.A. Goddard III, First Principles Calculations of the $p K_{a}$ Values and Tautomers of Isoguanine and Xanthine, Chem. Res. Toxicol. 16, 1455- 1462 (2003).

[28] Y.H. Jang, W.A. Goddard III, K.T. Noyes, L.C. Sowers, S. Hwang, D.S. Chung, $p K_{a}$ Values of Guanine in Water: Density Functional Theory Calculations Combined with Poisson-Boltzmann Continuum-Solvation Model. J. Phys. Chem. B 107, 344-357 (2003).

[29] A. Rich, in: M. Kasah, B. Pullman, (ed) Horizons in Biochemistry, Academic Press, New York 1962.

[30] H. Kamiya, Mutagenic potentials of damaged nucleic acids produced by reactive oxygen/nitrogen species: approaches using synthetic oligonucleotides and nucleotides: SURVEY AND SUMMARY. Nucl. Acids Res. 31 (2), 517-531 (2003).

[31] C. Roberts, R. Banduru, C. Switzer, Theoretical and Experimental Study of Isoguanine and Isocytosine: Base Pairing in an Expanded Genetic System. J. Am. Chem. Soc. 119, 4640-4649 (1997).

[32] X. Chen, R. Kierzek, D.H. Turner, Stability and Structure of RNA Duplexes Containing Isoguanosine and Isocytidine. J. Am. Chem. Soc. 123, 1267-1274 (2001).

[33] J.R. Blas, F.J. Luque, M. Orozco, Unique Tautomeric Properties of Isoguanine. J. Am. Chem. Soc. 126, 154-164 (2004).

[34] Y.H. Jang, L.C. Sowers, T. Cagin, W.A. Goddard III, First Principles Calculation of $p K_{a}$ Values for 5-Substituted Uracils. J. Phys. Chem. A 105, 274-280 (2001).

[35] B.P. Cho, F.F. Kadlubar, S.J. Culp, F.E. Evans, $15 N$ nuclear magnetic resonance studies on the tautomerism of 8-hydroxy-2'-deoxyguanosine, 8-hydroxyguanosine, and other C8-substituted guanine nucleosides. Chem. Res. Toxicol. 3, 445-452 (1990).

[36] B.P. Cho, Structure of oxidatively damaged nucleic acid adducts: PH dependence of the ${ }^{13} \mathrm{C} N \mathrm{NR}$ spectra of 8-oxoguanosine and 8-oxoadenosine. Magn. Reson. Chem. 31, 1048-1053 (1993).

[37] J. Gu, A. Tian, W.K. Li, and N.B. Wong, Intramolecular proton transfer in the tautomers of $\mathrm{C} 8$ oxidative adenine: A DFT study. J. Phys. Chem. B 104, 10692-10698 (2000).

[38] J.H. Miller, C.C.P. Fan-Chiang, T.P. Straatsma, M.A. Kennedy, 8-Oxoguanine enhances bending of DNA that favors binding to glycosylases. J. Am. Chem. Soc. 125, 6331-6336 (2003). 
[39] K. Song, V. Hornak, C. De Los Santos, A.P. Grollman, C. Simmerling, Molecular mechanics parameters for the FapydG DNA lesion. J. Comput. Chem. 29, 17-23 (2008).

[40] D.E. Volk, V. Thiviyanathan, A. Somasunderam, D.G. Gorenstein, Ab initio base-pairing energies of an oxidized thymine product, 5-formyluracil, with standard DNA bases at the BSSE-free DFT and MP2 theory levels. Org. Biomol. Chem. 5, 1554-1558 (2007).

[41] J.V. Burda, J. Šponer, J. Hrabadkova, M. Zeizinger, J. Leszczynski, The Influence of $N_{7}$ Guanine Modifications on the Strength of Watson-Crick Base Pairing and Guanine $N_{l}$ Acidity: Comparison of Gas-Phase and Condensed-Phase Trends. J. Phys. Chem. B 107, 5349-5356 (2003).

[42] T.K. Ha, H.J. Keller, R. Gunde, H.H. Gunthard, Quantum chemical study of structure and stability of all 14 isomers of isocytosine 1. J. Mol. Struct. 376, 375-397 (1996).

[43] P. Cysewski, D. Jeziorek, R. Oliński, Ab ab initio SCF study on the tautomerisation of fapy-guanine. J. Mol. Struct. THEOCHEM 369, 93-104 (1996).

[44] P. Cysewski, C. Vidal-Madjar, R. Jordan, R. Oliński, Structure and properties of hydroxyl radical modified nucleic acid components: II. 8-oxoadenine and 8-oxo-2'-deox-yadenosine. J. Mol. Struct. THEOCHEM 397, 167-177 (1997).

[45] P. Cysewski, D. Jeziorek, An ab inito SCF study on the tautomerisation of the 8-oxo-guanine and xanthine. J. Mol. Struct. THEOCHEM 430, 219-229 (1998).

[46] P. Cysewski, D. Jeziorek, R. Oliński, Structure and tautomeric properties of thymine derivatives generated by hydro$x y l$ radical in aerobic conditions, J. Chem. Soc. Faraday Trans. 94, 1813-1821 (1998).

[47] P. Cysewski, D. Jeziorek, R. Oliński, W. Woźnicki, $A b$ initio studies on the structure and properties of the hydroxyl radical modified adenine derivatives in different tautomeric forms, J. Phys. Chem. 99, 9702-9708 (1995).

[48] P. Cysewski, C. Vidal-Madjar, V. Noinville, R. Oliński, Structure and properties of hydroxyl radical modified nucleic acid components:I. 2-oxoadenine and 2'deoxy-8oxo-adenosine. Bul. Soc. Chim. Fr. 132, 453-460 (1995).

[49] K. Białkowski, P. Cysewski, R. Oliński, Effect of 2 '-deoxyguanine oxidation at $C 8$ position on the $N$-glycosidic bond stability. Z. Naturforschung 51C, 119-122 (1996).

[50] P. Cysewski, An ab initio study of the tautomeric and coding properties of 8-oxo-guanine. J. Chem. Soc. Faraday Trans. 94, 3117-3125 (1998).

[51] P. Cysewski, Theoretical studies on the tautomeric properties of diamino-5-formamidopyrimidines. Z. Naturforschung 53C, 1027-1036 (1998).

[52] P. Cysewski, Structure and properties of hydroxyl radical modified nucleic acid components: IV tautomerism and miscoding properties of 5-hydroxycytosine. J. Mol. Struct. THEOCHEM 466, 49-58 (1999).

[53] P. Cysewski, D. Jeziorek, R. Oliński, Structure and tautomeric properties of cytosine derivatives generated by a hydroxyl radical in aerobic conditions. J. Mol. Struct. THEOCHEM 459, 1-14 (1999).

[54] P. Cysewski, Structure and properties of hydroxyl radical modified nucleic acid components: pairing properties of 2hydroxyadenine and 8-oxoadenine. J. Mol. Struct. THEOCHEM 466, 59-67 (1999).

[55] P. Cysewski, Structure and tautomeric properties of thymine derivatives generated by hydroxyl radical in anaerobic conditions. J. Mol. Struct. THEOCHEM 467, 51-61 (1999).

[56] P. Cysewski, R. Oliński, Ab initio quantum chemistry studies on the coding properties of cytosine derivatives generated by hydroxyl radical in aerobic conditions. J. Mol. Struct. THEOCHEM 490, 69-79 (1999).
[57] P. Cysewski, R. Oliński, Theoretical description of the coding potential of diamino-5-formamidopyrimidines, $\mathrm{Z}$. Naturforschung 54C, 239-245 (1999).

[58] P. Cysewski, Coding properties of thymine derivatives generated by hydroxyl radical in aerobic conditions, Phys. Chem. Chem. Phys. 1, 1531-1537 (1999).

[59] P. Cysewski, Ab initio calculations of the pairing of four canonical DNA bases with three thymine derivatives generated by hydroxyl radical in anaerobic conditions, Pol. J. Chem. 74, 245-256 (2000).

[60] P. Cysewski, D. Bira, K. Strzelecka, Proton affinities and $N$-glycosidic bond stabilities of hydroxyl radical modified adenosine. Phys. Chem. Chem. Phys. 5, 4899-4904 (2003).

[61] P. Cysewski, D. Bira, K. Białkowski, An ab initio quantum chemistry study on $\mathrm{N}$-glycosidic bond stabilities of hydroxyl radical modified guanosine analogs. J. Mol. Struct. THEOCHEM 678, 77-81 (2004).

[62] P. Cysewski, An ab initio DFT characteristics of tautomeric properties of hydroxyl radical modified nucleosides in polar and non-polar environments. Z. Phys. Chem. 219, 213-234 (2005).

[63] P. Cysewski, An ab initio study on nucleic acid bases aromaticities. J. Mol. Struct. THEOCHEM 714, 29-34 (2005).

[64] P. Cysewski, K. Kozłowska, Accurate gas phase basicities of hydroxyl radical modified purines estimated by advanced quantum chemistry methods, Pol. J. Chem. 82, 2255-2268 (2008).

[65] P. Cysewski, The impact of the nucleoside oxidation on the susceptibility to chemical carcinogens studied by first principle and semiempirical quantum chemistry methods. J. Mol. Struct. THEOCHEM 863, 16-21 (2008).

[66] P. Cysewski, Intra-strand stacking interactions in B-DNA crystals characterized by post-SCF quantum chemistry computations. New J. Chem. 33, 1909-1917 (2009).

[67] P. Cysewski, The post-SCF quantum chemistry characteristics of inter- and intra-strand stacking interactions in $d(C p G)$ and $d(G p C)$ steps found in B-DNA, A-DNA and $Z$-DNA crystals. Journal of Molecular Modeling 15(6), 597606 (2009).

[68] P. Cysewski, K. Kozłowska, B. Szefler, Accurate microand macro- gas phase basicities of hydroxyl-radicalmodified pyrimidines estimated by advanced quantum chemistry methods. Journal of Molecular Modeling 15(6), 711-722 (2009).

[69] P. Cysewski, P. Czeleń, Structural and energetic heterogeneities of canonical and oxidized central guanine triad of $B-D N A$ telomeric fragments. Journal of Molecular Modeling 15(6), 607-613 (2009).

[70] A.D. Becke, Density-functional thermochemistry. III. The role of exact exchange. J. Chem. Phys. 98, 5648-5652 (1993).

[71] J. Tomasi, R. Cammi, B. Mennucci, C. Cappelli, S. Corni, Molecular properties in solution described with a continuum solvation model. Phys. Chem. Chem. Phys. 4, 5697$5712(2002)$.

[72] A. Bondi, van der Waals Volumes and Radii. J. Phys. Chem. 68, 441-451 (1964).

[73] M.J. Frisch, G.W. Trucks, H.B. Schlegel, G.E. Scuseria, M.A. Robb, J.R. Cheeseman, J.A. Montgomery Jr, T. Vreven, K.N. Kudin, J.C. Burant, J.M. Millam, S.S. Iyengar, J. Tomasi, V. Barone, B. Mennucci, M. Cossi, G. Scalmani, N. Rega, G.A. Petersson, H. Nakatsuji, M. Hada, M. Ehara, K. Toyota, R. Fukuda, J. Hasegawa, M. Ishida, T. Nakajima, Y. Honda, O. Kitao, H. Nakai, M. Klene X. Li, J.E. Knox, H.P. Hratchian, J.B. Cross, V. Bakken, C. Adamo, J. Jaramillo, R. Gomperts, R.E. Stratmann, 
O. Yazyev, A.J. Austin, R. Cammi, C. Pomelli, J.W. Ochterski, P.Y. Ayala, K. Morokuma, G.A. Voth, P. Salvador, J.J. Dannenberg, V.G. Zakrzewski, S. Dapprich, A.D. Daniels, M.C. Strain, O. Farkas, D.K. Malick, A.D. Rabuck, K. Raghavachari, J.B. Foresman, J.V. Ortiz, Q. Cui, A.G. Baboul, S. Cliord, J. Cioslowski, B.B. Stefanov, G. Liu, A. Liashenko, P. Piskorz, I. Komaromi, R. L. Martin, D.J. Fox, T. Keith, M.A. Al-Laham, C.Y. Peng, A. Nanayakkara, M. Challacombe, P.M.V. Gill, B. Johnson, W. Chen, M. W. Wong, C. Gonzalez, J.A. Pople, Gaussian 03, Revision C.02, Gaussian, Wallingford CT., 2004.

[74] G.J. Fogarasi, High-level electron correlation calculations on some tautomers of cytosine. Mol. Struct. 413, 271-278 (1997).

[75] J. Leszczynski, Tautomerism of uracil: the final chapter? Fourth-order electron correlation contributions to the relative energies of tautomers. J. Phys. Chem. 96, 1649-1653 (1992).

[76] R.J. Kobayashi, A CCSD(T) Study of the Relative Stabilities of Cytosine Tautomers. Phys. Chem. A 102, 10813-10817 (1998).

[77] H.Y. Afeefy, J.F. Liebman, S.E. Stein, Neutral Thermochemical Data in NIST Chemistry WebBook, NIST Standard Reference Database Number 69, (ed.) P.J. Linstrom, W.G. Mallard, 6http://webbook.nist.gov National Institute of Standards and Technology, Gaithersburg 2005.

[78] Y. Podolyan, L. Gorb, J. Leszczynski, Protonation of Nucleic Acid Bases. A Comprehensive Post-Hartree-Fock Study of the Energetics and Proton Affinities. J. Phys. Chem. A 104, 7346-7352 (2000).

[79] A.R. Katritzky, J.M. Lagowski, Prototropic Tautomerism of Heteroaromatic Compounds: 3. Five-Membered Rings and One Hetero Atom. Adv. Heterocycl. Chem. 1, 311-325 (1963).

[80] E.D. Raczyńska, W. Kosińska, B. Ośmiałowski, R. Gawinecki, Tautomeric Equilibria in Relation to Pi-Electron Delocalization. Chem. Rev. 105, 3561-3612 (2005).

[81] L.M. Cunane, M.R. Taylor, The Effects of Metal Binding on a Nucleobase: the Experimental Charge Density and

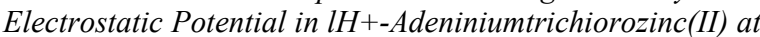
$123 \mathrm{~K}$ and its Relationship to that in Adenine Hydrochloride Hemihydrate. Acta Crystallogr. D 53, 765-776 (1997).

[82] W. Saenger, Principles of Nucleic Acid Structure. SpringerVerlag, Berlin 1988.

[83] R.R. Sinden, DNA Structure and Function. Academic Press, San Diego 1994.

[84] I.A. Topol, G.J. Tawa, S.K. Burt, A.A. Rashin, Calculation of Absolute and Relative Acidities of Substituted Imidazoles in Aqueous Solvent. J. Phys. Chem. A. 101, 10075-10081 (1997).

[85] C. Lim, D. Bashford, M. Karplus, Absolute pKa calculations with continuum dielectric methods, J. Phys. Chem. 95, 5610-5620 (1991).

[86] M.D. Tissandier, K.A. Cowen, W.Y. Feng, E. Gundlach, M. J. Cohen, A.D. Earhart, J.V. Coe, The Proton's Absolute Aqueous Enthalpy and Gibbs Free Energy of Solvation from Cluster-Ion Solvation Data. J. Phys. Chem. A 102, 77877794 (1998).

[87] C.P. Kelly, C.J. Cramer, D.G. Truhlar, Aqueous Solvation Free Energies of Ions and Ion-Water Clusters Based on an Accurate Value for the Absolute Aqueous Solvation Free Energy of the Proton, J. Phys. Chem. B 110, 16066-16081 (2006).

[88] M.B.C. Leao, A.C. Pavao, Molecular Orbital Analysis of Chemical Carcinogens. Int. J. Quantum Chem. 62, 323-328 (1997).
[89] M.B. C. Leao, R.L. Longo, A.C. Pavao, A molecular orbital analysis of the DNA bases. J. Mol. Struct. THEOCHEM 490, 145-153 (1999).

[90] M.B.C. Leao, A.C. Pavao, v. A.A. Espinoza, C.A. Taft, E.P. Bulnes, A multivariate model of chemical carcinogenesis. J. Mol. Struct. THEOCHEM 719, 129-135 (2005).

[91] E.C. Miller, Some current perspectives on chemical carcinogenesis in humans and experimental animals: Presidential Address. Cancer Res. 38, 1479-1496 (1978).

[92] B. Vogelstein, K.W. Kinzler, Carcinogens leave fingerprints, Nature 355, 209-210 (1992).

[93] B. Armitage, Photocleavage of Nucleic Acids, Chem. Rev. 98, 1171-1200 (1998).

[94] C.J. Barrows, J.G. Muller, Oxidative Nucleobase Modifications Leading to Strand Scission. Chem. Rev. 98, 11091152 (1998).

[95] E. Meggers, M.E. Michel-Beyerle, B. Giese, Sequence Dependent Long-Range Hole Transport in DNA. J. Am. Chem. Soc. 120, 12950-12955 (1998).

[96] H. Sugiyama, I. Saito, Theoretical Studies of GG-Specific Photocleavage of DNA via Electron Transfer: Significant Lowering of Ionization Potential and 5'-Localization of HOMO of Stacked GG Bases in B-Form DNA. J. Am. Chem. Soc. 118, 7063-7068 (1996).

[97] P. Wolf, G.D.D. Jones, L.P. Candeias, L.P. O’Neil, Introduction of Strand Breaks in Polynucleotides and DNA by Sulfate Radical Anion: Role of Electron Loss Centres as Precursors of Strand Breakage. Int. J. Radiat. Biol. 64, 7-18 (1993).

[98] L. Fairall, L. Chapman, H. Moss, T. de Lange, D. Rhodes, Structure of the TRFH Dimerization Domain of the Human Telomeric Proteins TRF1 and TRF2. Mol. Cell. 8, 351-361 (2001).

[99] H. Yanagawa, Y. Ogawa, M. Ueno, Redox ribonucleosides. Isolation and characterization of 5-hydroxyuridine, 8hydroxyguanosine, and 8-hydroxyadenosine from Torula yeast RNA. J. Biol. Chem. 267, 13320-13326 (1992).

[100] S. Kawanishi, Y. Hiraku, M. Murata, S. Oikawa, The role of metals in site-specific DNA damage with reference to carcinogenesis. Free Radic. Biol. Med. 32, 822-832 (2002).

[101] P.G. Slade, M.K. Hailer, B.D. Martin, K.D. Sugden, Guanine-specific oxidation of double stranded DNA by $\mathrm{Cr}(V I)$ and ascorbic acid forms spiroiminodihydantoin and 8-oxo2'-deoxyguanosine. Chem. Res. Toxicol. 18, 1140-1149 (2005).

[102] C.A.M. Seidel, A. Schulz, M.H.M. Sauer, NucleobaseSpecific Quenching of Fluorescent Dyes. 1. Nucleobase One-Electron Redox Potentials and Their Correlation with Static and Dynamic Quenching Efficiencies. J. Phys. Chem. 100, 5541-5553 (1996).

[103] H.E. Krokan, R. Standal, G. Slupphaug, DNA glycosylases in the base excision repair of DNA. Biochem. J. 325, 1-16 (1997).

[104] P.M. Wright, J. Yu, J. Cillo, A.L. Lu, The active site of the Escherichia coli mutY DNA adenine glycosylase. J. Biol. Chem. 274, 29011-29018 (1999).

[105] J. Hovinen, C. Glemarec, A. Sandström, C. Sund, J. Chattopadhyaya, Spectroscopic, kinetic and semiempirical molecular orbital studies on 8-amino-, 8-methylamino-\& 8-dimethylamino-adenosines. Tetrahedron 47, 4693-4708 (1991).

[106] J.A. Zoltewicz, D.F. Clark, T.W. Sharpless, G. Grahe, Kinetics and mechanism of the acid-catalyzed hydrolysis of some purine nucleosides. J. Am. Chem. Soc. 92, 1741-1750 (1970). 
[107] S.F. Boys, F. Bernardi, The calculation of small molecular interactions by the differences of separate total energies. Some procedures with reduced errors. Mol. Phys. 19, 553566 (1970).

[108] H. Kasai, H. Tanooka, S. Nishimura, Formation of 8-hydroxyguanine residues in DNA by $X$-irradiation. Gann. 75 , 1037-1039 (1984).
[109] P. Cysewski, Opis właściwości tautomerycznych i kodujacych produktów wolnorodnikowych uszkodzeń zasad azotowych. Bydgoszcz 1999.

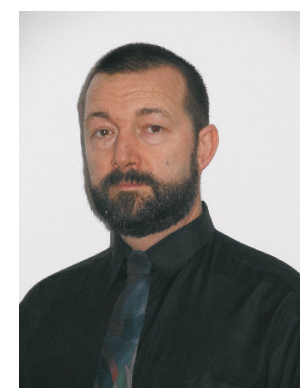

Piotr Cysewski, PhD, DSci. is Director of Physical Chemistry Department, Ludwik Rydygier Collegium Medicum of Bydgoszcz, Nicolaus Copernicus University in Torun, ul. Kurpińskiego 5, 85-950 Bydgoszcz, Poland. As an absolvent of the Nicolaus Copernicus University (1984) his PhD dissertation presented at this University four years later. In 2000 reached DSci level at the Polish Academy of Science, Bioorganic Chemistry Institute in Poznań. Since 2006 has Professor position at the Nicolaus Copernicus University. Also since 2004 is Professor of University of Technology and Natural Sciences in Bydgoszcz. He utilizes molecular modeling tools for description of properties of bio-organic compounds. Apart from hydroxyl radical analogues of nucleobases also mechanisms of radical polymerizations, aromatic properties of organic compounds, stacking interactions, recognition patterns, telomeric B-DNA structure and dynamics are of particular interests. Main scientific interests comprise (i) molecular basis of observed biochemical consequences of free radical modified nucleobases and nucleosides, especially tautomeric equilibriums, protolytic properties, coding abilities, inter-strand and intra-strand stacking, N-glycosidic bond stabilities, etc. (ii) structural and energetic diversities of modified double stranded DNA in different polymorphic forms (iii) environment influence on the heterogeneities of aromaticities of amino acids, canonical and modified nucleobases and (iv) intermolecular interactions with amino acids as the source of recognition of modified nucleobases. He is an author of 60 papers in peer reviewed journals. 